\title{
Dans la Trajectoire des Choses
}

Comparaison des approches francophones et anglophones

contemporaines en anthropologie des techniques

\section{Ludovic Coupaye et Laurence Douny}

\section{(2) OpenEdition}

1 Journals

Édition électronique

URL : https://journals.openedition.org/tc/4956

DOI : $10.4000 /$ tc. 4956

ISSN : 1952-420X

Éditeur

Éditions de l'EHESS

\section{Édition imprimée}

Date de publication : 1 décembre 2009

Pagination : 12-39

ISBN : 978-2-7351-1301-9

ISSN : 0248-6016

Référence électronique

Ludovic Coupaye et Laurence Douny, «Dans la Trajectoire des Choses », Techniques \& Culture [En ligne], 52-53 | 2009, mis en ligne le 27 août 2012, consulté le 29 septembre 2022. URL : http:// journals.openedition.org/tc/4956; DOI : https://doi.org/10.4000/tc.4956 


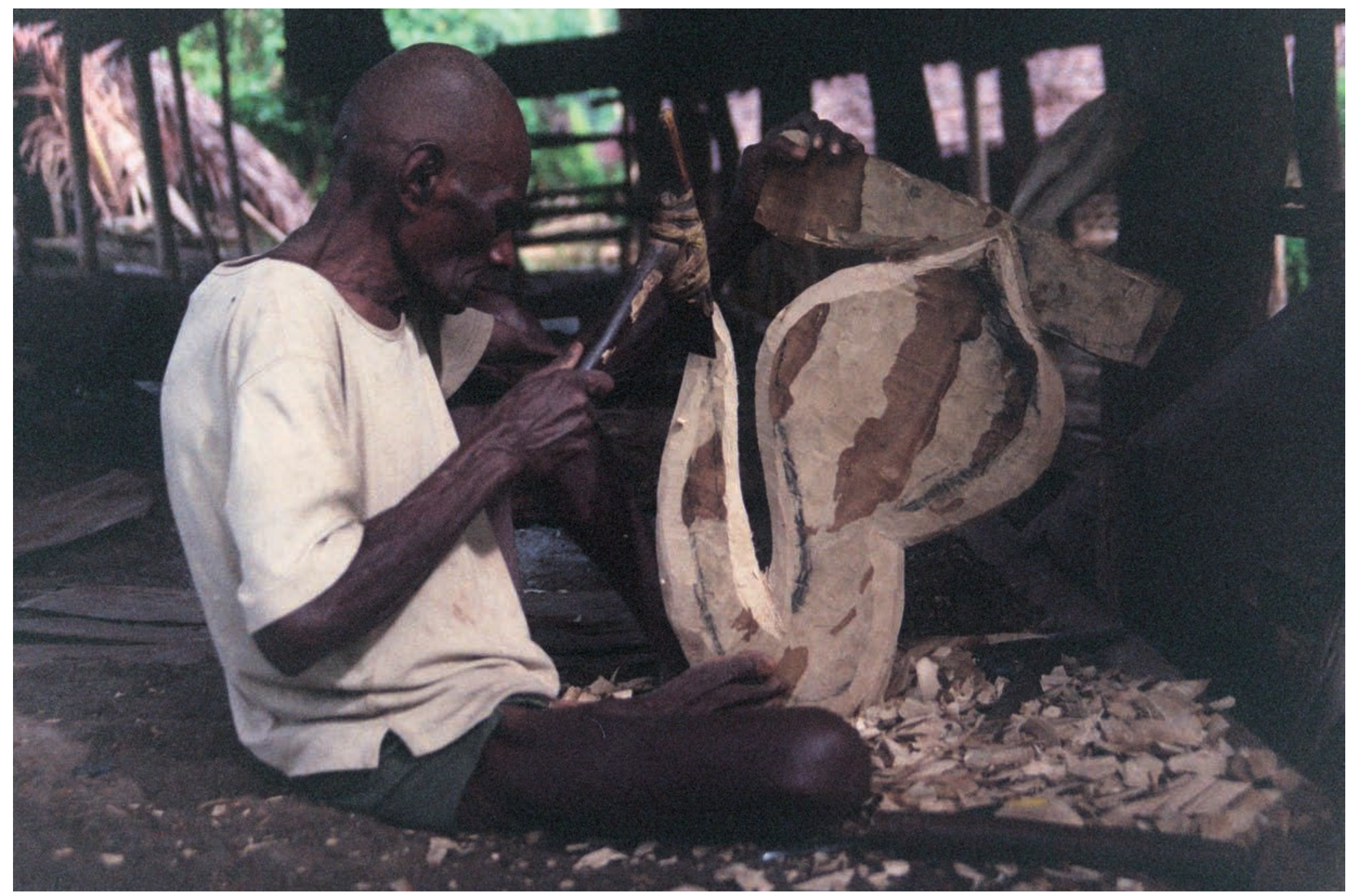

${ }^{\circ}$ L. Coupaye 


\title{
DANS LA TRAJECTOIRE DES CHOSES
}

\section{Comparaison des approches \\ francophones et anglophones contemporaines \\ en anthropologie des techniques}

\begin{abstract}
Où il sera question de dialogues, de malentendus des deux côtés de la Manche mais aussi de l'actualité la plus brûlante de la recherche en anthropologie des techniques.
\end{abstract}

Le titre général de ce Thema, «Technologies», peut être lu de différentes façons. La première, bien sûr, évoque les travaux des nombreux auteurs qui ont été à l'origine de la revue Techniques \& culture, à une époque où la « technologie culturelle» était en plein essor. La seconde renvoie au cœur de ce dossier qui souhaite présenter et comparer quelques-unes des études britanniques de ce que l'on nomme outre-Manche «technology». En outre, le pluriel, technologies, fait sens dans les deux langues, française et anglaise. La troisième acception se veut plus précise. En partant de la définition donnée par Haudricourt $(1968,1987)$ et reprise par Sigaut (1985, 2002 [1994]), nous pouvons en effet comprendre le terme « technologie » comme désignant la science qui étudie les faits techniques - de même que la géo-logie est la science qui étudie la terre. En utilisant technologies, nous pouvons ainsi faire référence aux sciences qui étudient les faits techniques et plus précisément aux différentes approches scientifiques des faits techniques.

Quant au titre de cette introduction, « Dans la trajectoire des choses », il fait référence aux approches des techniques dans les traditions anglophones et francophones, mais aussi aux études des rapports entre sociétés et objets 
qui sont consacrées aux biographies (Kopytoff 1986) ou aux carrières d'objets (Bromberger \& Chevallier 1999). Par ailleurs, ce terme renvoie aussi à nos propres parcours entre France et Angleterre et qui nous permettent aujourd'hui de relancer le dialogue entre deux « traditions » anthropologiques, au Royaume-Uni et en France ${ }^{1}$.

Le terme de «traditions » de recherche - notamment pour les anthropologues - est incorrect, bien sûr, mais il exprime bien ce que nous définirions ici comme ces trajectoires académiques (institutionnelles) et scientifiques (théoriques) qui donnent leur forme à des catégories et à des sujets d'études, ainsi qu'à leur traitement théorique et méthodologique. On parlera dans cet article des traditions anglo-saxonnes et françaises d'étude des techniques au sein de la culture matérielle. Ces traditions concernent une à deux générations de chercheurs et d'étudiants qui, en raison de leur intérêt pour la culture matérielle, ont orienté leurs parcours académiques de façon interdisciplinaire dans les secteurs de l'anthropologie, la préhistoire, l'archéologie, la sociologie, la muséologie, l'histoire, ou l'histoire de l'art, passant du monde francophone à l'anglophone, ou inversement. En ce qui concerne la Grande-Bretagne et la France, ces différences d'approche ont pu être formulées de manière parfois tranchée. Ainsi, Chevallier (1998), Faure-Rouesnel (2001) de même que Julien \& Rosselin (2005) ont pu parler de distinction dans l'étude de la culture matérielle entre les francophones, chez lesquels prédomine l'étude des techniques, et les anglophones, plus particulièrement les Britanniques, intéressés plutôt par l'étude de la consommation.

Nous ferons ici une rapide esquisse de ces trajectoires de recherche, en commençant par le contexte britannique, et soulèverons les divers enjeux théoriques et anthropologiques qui sous-tendent les recherches sur la culture matérielle.

\section{Technologie et Material Culture Studies}

Si en France, les techniques sont des axes courants de recherche de l'anthropologie, l'étude des techniques en Grande-Bretagne et aux États-Unis renvoie à une tradition qu'il est plus difficile de cerner, notamment parce que le sujet n'est pas fixé sous la forme d'une approche possédant sa propre dénomination, contrairement à la « technologie culturelle » française des années soixante-dix. Les raisons en sont probablement multiples, dues entre autres à l'absence en Grande-Bretagne d'une ethnographie locale, qui, comme en Allemagne ou en France, aurait pu attirer l'attention des chercheurs sur les transformations profondes des pratiques techniques, notamment les pratiques agricoles, au xix ${ }^{e}$ siècle et au début du xx $x^{e}$ siècle.

Par ailleurs, telle qu'elle se dessine de Boas à Ingold, en passant par Lechtman (1977) et Ucko (1969), l'étude anglophone de la culture matérielle est l'héritière du divorce, déjà vieux et global, signalé dès la fin des années 
soixante, entre l'anthropologie et les musées (cf. Ucko 1969 ; Sturtevant 1969). Ce divorce s'ancre dans un rejet des modèles, jugés trop spéculatifs et réducteurs, des approches évolutionnistes ou diffusionnistes mais aussi sur le refus d'une conception essentiellement «économiste » des techniques. Même lorsqu'il s'agit d'aborder la technique d'un point de vue critique, comme chez des auteurs tels que l'Américain White (1959), les approches des techniques par l'économie restent trop souvent déterministes (Gosden 1999 : 88-89, 160). Le caractère social des faits techniques est pourtant loin d'être complètement absent du paysage universitaire britannique. Si la philosophie des techniques y occupe une position relativement privilégiée (cf. notamment les ouvrages de Mumford ou encore le volume édité par Mitcham \& MacKey en 1972), l'histoire y occupe également une place prépondérante, que ce soit en Grande-Bretagne ou en Amérique du Nord. Cette approche historique et sociale se retrouve notamment dans les préoccupations de la Société pour l'histoire des techniques (Society for the History of Technology, SHOT), fondée entre autres par White et Mumford et dont la revue, créée en 1958, Technology and Culture, porte un nom jumeau de la présente Techniques E culture. Pourtant, cette école subit elle-même des tensions épistémologiques internes entre approches classiques et approches plus contextualisées qui, tout en variant les sujets (innovation, relation science-technologie, manufacture), les limitent aux domaines occidentaux et laissent peu de place à des exemples anthropologiques (Staudenmaier 1990 : 724). Peut-être faut-il y voir une sorte de cercle vicieux dans lequel l'anthropologie anglo-saxonne s'intéressant peu aux techniques, celles-ci restent le territoire des approches historiennes et sociologiques. Ces dernières, à leur tour, ne profitant pas ou fort peu du décentrement du regard qu'offre l'approche ethnographique, en viennent à aborder surtout des problématiques proches des préoccupations des sociétés occidentales.

Pour qu'un dialogue puisse s'établir, il faudra attendre les années soixantedix lorsque les questions et les méthodologies issues de l'analyse sociologique des sciences pénètrent au sein des études des techniques (Cohen \& Pestre 1998), menant au développement des travaux des SCOT (Social Contruction of Technology, Bijsker, Hugues \& Pinch 1987) ainsi qu'aux apports de Callon, Latour et Law (Latour \& Woolgar 1979, traduit en français en 1988) et des STS (Sciences and Technology Studies). Cette transformation dans les études des techniques oriente alors les réflexions dans une direction qui permet des passages vers les questions anthropologiques telles qu'elles sont posées en France. Cette partie de la trajectoire des techniques anglo-saxonnes passera également par le domaine francophone, comme on le verra. Mais, force est de constater que dans ce domaine, comme dans le cas de la French Theory, le succès des recherches menées par les représentants de l'actor-network theory (cf. Law 1990) occupe un espace important, dans lequel l'anthropologie des techniques à la française a du mal à se placer. En conséquence, la prédominance des travaux des historiens et des sociologues des sciences dans les discussions autour des faits techniques est telle qu'elle parvient à occulter la technologie culturelle et à occuper une place privilégiée dans les études anglophones d'anthropologie de la culture matérielle ( $c f$. citations faites par 


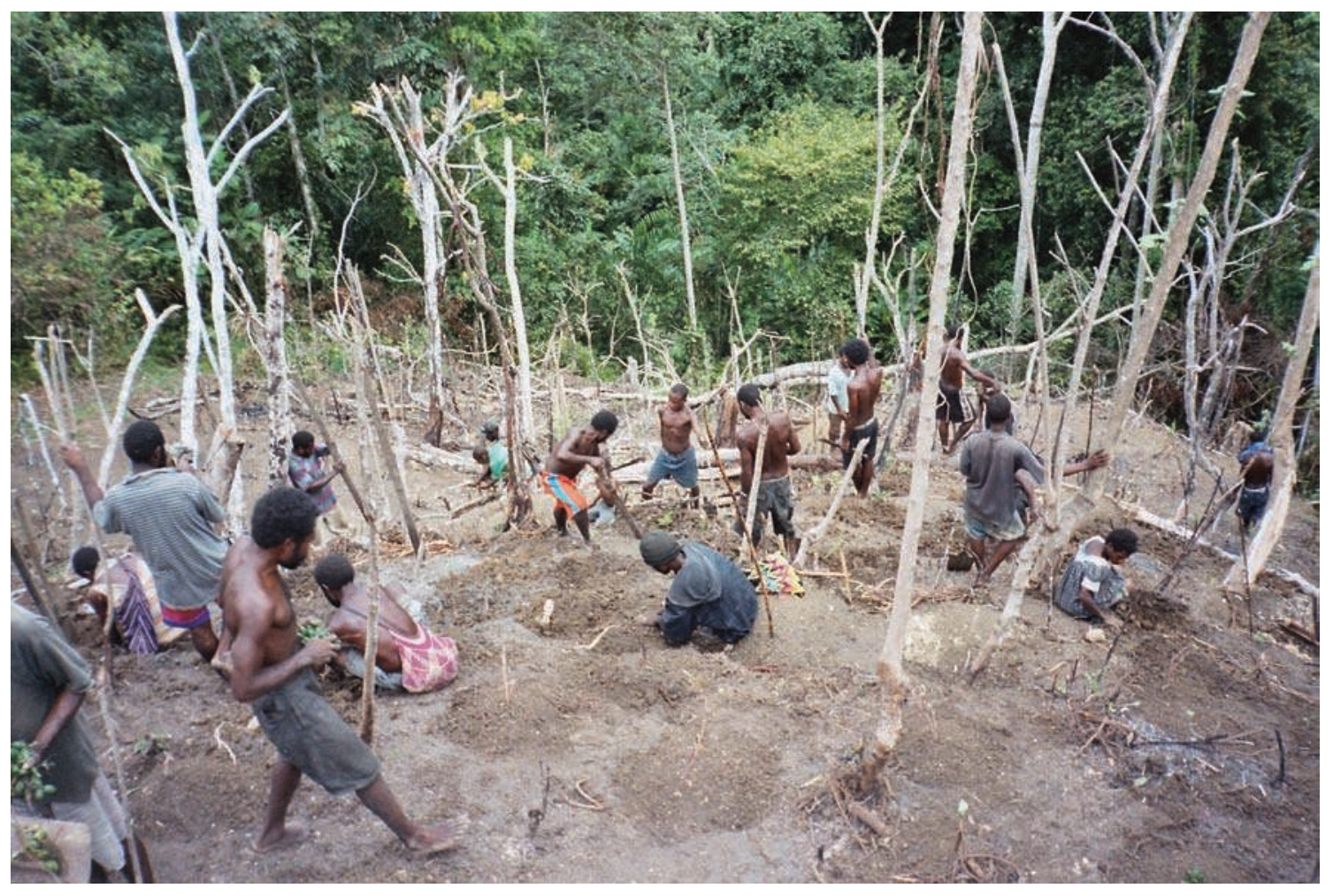

Plantation dans un jardin de petites ignames

Un groupe de 48 personnes, hommes, femmes et enfants, appartenant à deux hameaux du village de Nyamikum sont rassemblés afin de planter le jardin de Moses Bakenose. Les jeunes hommes manient la bêche en palmier noir, creusant les trous où les membres plus âgés, les enfants et les femmes placeront les boutures d'ignames. Le processus de plantation suit un ordre strict, dirigé par Moses qui, aidé de ses fils, répartit les boutures près de chaque trou, faisant correspondre cultivar et type de terrain. L'ensemble de la session est entrecoupée de plaisanteries censées donner du cœur à l'ouvrage, mettant en exergue l'importance des relations sociales dans le succès de l'opération. Les substances corporelles des participants (masculins comme féminins) sont dites se mélanger et entrer dans la terre, pour contribuer activement à la pousse des ignames. (Photo : Nyamikum, ESP, PNG, 25.11.2002).
Küchler \& Were, ce volume). En effet, si en France la trajectoire des études des techniques est indissociable de celles de la culture matérielle (Lemonnier 1986), on ne peut pas en dire autant du contexte anglophone. Si la culture matérielle est bien au centre des préoccupations des archéologues, elle l'est moins dans celles des anthropologues britanniques. Il faut attendre la fin des années soixante pour que les objets refassent leur apparition au sein des programmes de recherches anthropologiques.

Ce retour profite, semble-t-il, de trois tendances majeures sur lesquelles on dira quelques mots, car il semble qu'elles aient joué un rôle dans l'absence des techniques des débats anglophones. D'une part, le retour progressif de la culture matérielle se fait surtout sous l'influence de la critique marxiste (cf. Miller ce volume) du capitalisme anglo-saxon et se focalise davantage sur la distribution et la consommation de la triade marxienne (Douglas \& Isherwood 1979). D'autre part, ce retour résulte d'une sorte de double tendance, en apparence paradoxale, mais complémentaire, double tendance qui peut permettre d'éclairer la position de la technologie dans ces études : d'un côté, on assiste à une attention de plus en plus forte portée aux phénomènes dits « postcoloniaux » et de « globalisation » et à l'émergence de politiques tournées vers les minorités et vers des questions de développement. Curieusement, l'influence dans les études françaises dans ce domaine de l'anthropologie anglophone viendra moins de l'anthropologie 
elle-même que de la réappropriation de la « French Theory » et des débats et des dissidences qu'elle va susciter - comme le démontre Cusset (2003) pour les États-Unis. Ainsi, dans un récent ouvrage anglophone présentant l'anthropologie dans les quatre principaux pays où elle s'est développée (Barth \& al. 2005), la présentation des traditions françaises insiste sur l'importance de Baudrillard, Foucault, Lacan et Lyotard, très peu mobilisés par les ethnologues français. Cette forme de réinterprétation du « poststructuralisme à la française » se combine au succès croissant des Cultural Studies, d'abord sous sa version anglaise à Birmingham (Grossberg 1996) puis sous sa version américaine d'American studies. Ces deux tendances vont alors largement influencer les questions anthropologiques articulées à des notions telles que l'identitélethnicité, les diasporas, la sexualité, l'anthropologie appliquée et la fameuse notion de modernité. Dans cette mouvance théorique, les objets qui pendant longtemps ont été écartés du centre des préoccupations des anthropologues, reprennent valeur de signes et de textes, qu'il importe de questionner.

On voit émerger une troisième tendance qui met en valeur le rôle politique des musées et qui illustre l'importance croissante de la place des images et de leur circulation. En s'interrogeant sur le rôle des artefacts dans la représentation, notamment des minorités, au sein des musées, ces questions éclairent leur dimension de cultural properties ou d'heritage (patrimoine, en France). En Grande-Bretagne, ces débats mettent en lumière un certain nombre de caractéristiques sémantiques et pragmatiques des objets et font surgir de nouvelles questions comme celle de l'authenticité (Kirshenblatt-Gimblet 1997 ; Steiner \& Phillips 1999).

Ces tendances se retrouvent dans une série de textes, aujourd'hui devenus emblématiques. Ainsi, les travaux de Stocking Jr. (1985), d’Appadurai (1986), de Kopytoff (1986), de Miller (1987) et de Thomas (1991) font partie des références des approches anthropologiques récentes de la culture matérielle (cf. Fabian $2004:$ 47). Si ces études analysent les modes de constitution des savoirs anthropologiques ou les modes de représentation de l'Autre, elles mettent également en lumière le rôle des objets comme signes dans ces processus liés au colonialisme, au postcolonialisme et à la globalisation. En revanche, la dimension technique des objets reste peu abordée en dépit de quelques études fondatrices associées au musée Pitt-Rivers (dont notamment celle de Blackwood 1950 et, plus récemment, de Wingfield et Petch²). Les cinq textes évoqués plus haut, notamment ceux d'Appadurai, de Kopytoff et de Miller, donnent le ton et constituent les références essentielles à citer dans les articles sur la culture matérielle anglo-saxonne : l'équivalent d'un Leroi-Gourhan ou d'un Cresswell pour la technologie culturelle française.

Les questions de globalisation et de modernité apparaissent alors centrales pour ces approches qui voient dans toute anthropologie classique une forme d'exotisme suspect et de romantisme méthodologiquement dangereux et qui ne rend pas compte du fait que l'économie de marché touche de plus en plus les sociétés traditionnelles. L'influence du marxisme anglophone permet alors de confronter les idées mises en avant par Mauss dans L'Essai sur le don (1950 [1923-1924], traduit pour la première fois en 
Fondation des murs et des compartiments du grenier sous le regard des enfants qui, par observation et participation, apprennent à reproduire les gestes du maçon

(Mali, 2008).
1954) avec une analyse marxienne de la marchandise (par exemple Gregory 1980, 1982). Cette influence invite alors une partie de l'anthropologie et de l'archéologie anglophone à une étude des échanges, comme un moyen de réfléchir à la manière dont les « choses », en circulant, participent à la construction des sociétés. Cette orientation semble alors pousser les études qu'on appelle « classiques » de la culture matérielle à lutter pour justifier leur place dans les anthropologies anglo-saxonnes, notamment face aux études sur la modernité, le développement, les diasporas ou les identités. Ce retour des objets paraît se faire principalement par une approche des pratiques, qui s'ancre dans la tradition marxiste britannique et dans une forme de critique de l'ultra-relativisme postmoderne. En revanche, ces analyses concernent non pas les manières de faire ou de fabriquer, mais la manière dont les objets s'échangent, circulent ou sont manipulés comme des signes. On leur attribue des « biographies »; ils traversent des « régimes de valeur» (Appadurai 1986 ; Kopytoff 1986) et contribuent (ou pas) à la contestation des « grandes narrations » occidentales, coloniales, masculines, hétérosexuelles, blanches. Combiné à la bouture anglophone du structuralisme et à sa mutation postmoderne, le moyen privilégié pour recommencer à parler des objets semble être l'étude de leurs utilisations sociales et culturelles qui permet d'affirmer, de confirmer ou de contester les discours concernant les sociétés. Dès que cet angle est adopté et en référence à Baudrillard $(1968,1973)$, on constate que la consommation ne

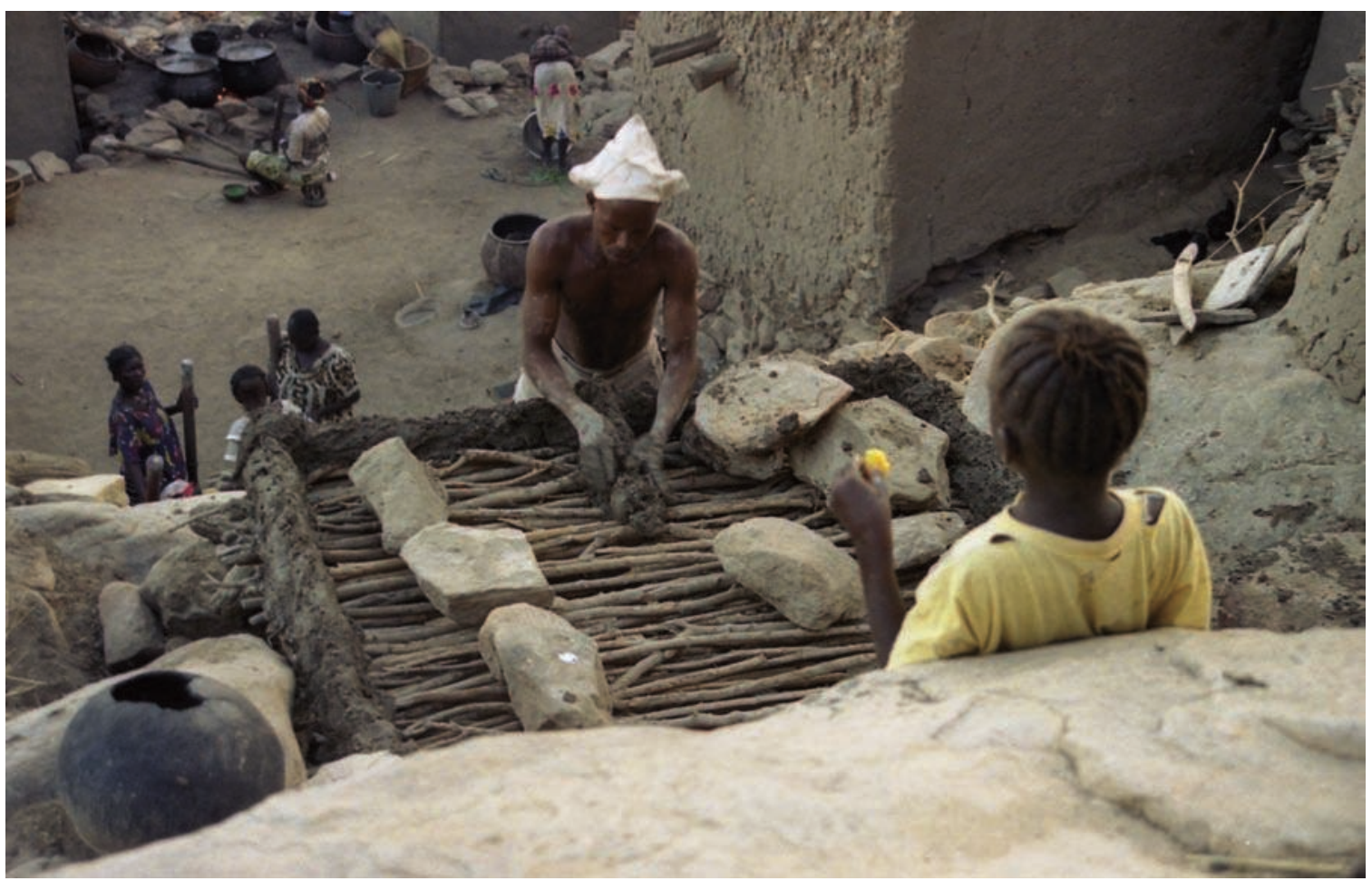


peut plus être considérée comme un simple phénomène de soumission à la modernité, dans lequel les « consommateurs » seraient les pions passifs du Marché Tout-Puissant - que l'on parle de « seniors » ou de la jeunesse friande de boissons gazeuses à Trinidad (Miller 1998). Au contraire, ce sont la réappropriation des produits consommés, la manipulation des symboles matériels, leur réinterprétation et leur usage politique au sein des institutions culturelles qui vont intéresser cette anthropologie de la culture matérielle.

Quant à la notion de technology, elle réapparaît en anthropologie sous de nouvelles formes qui tiennent à se démarquer nettement des explications trop linéaires et des approches historiennes « à la Pitt Rivers» ou « à la Leslie A. White ». Dans une évolution parallèle à celle qui a eu lieu en France, l'anthropologie britannique des objets prend une direction qui s'éloigne de la question des techniques, pour se focaliser davantage sur celle des pratiques associées aux usages. Dans cette optique, par les habitus auxquels ils sont associés, les objets participent aux procédés de socialisation que Foucault appelle les technologies (cf. Warnier ce volume, Warnier 2009b). Refusant la définition limitée que la langue anglaise octroie au terme « technology» (cf. Sigaut 1985, 2002 [1994]), la culture matérielle britannique, dans sa critique postmoderne des déterminismes, paraît donc lui préférer son usage métaphorique foucaldien. Par ailleurs, l'étude des techniques de l'anthropologie anglophone croise, bien sûr, celle de l'archéologie et c'est peut-être dans ce domaine que les dialogues et les influences s'établissent d'une manière plus visible. Elles font converger les travaux de la New Archaeology, de la Behavioral Archaeology ou des études postprocessuelles qui, à des degrés divers, ont orienté les réflexions vers l'étude des techniques, jusqu'alors limitée à des analyses plus archéométriques et fonctionnelles de la culture matérielle. C'est sans doute au travers des études ethnoarchéologiques, comme celles des ouvrages de Lechtman \& Merill (1977), de Yellen (1977) ou de Kramer (1979), mais aussi de Van der Leeuw $(1976,1991)$, et plus récemment de Schiffer (2001), de Sillar \& Tite (2000) et de Dobres (2000), que l'on retrouve des questions similaires à celles de l'anthropologie. Pourtant, le tournant postprocessualiste, influencé par le postmodernisme invite davantage les archéologues anglophones, notamment britanniques, à se détourner de sujets comme les techniques, où le déterminisme paraît encore trop présent, pour s'orienter vers des questions de sens et d'usage, sous l'influence combinée du structuralisme et de Marx (cf. Miller, ce numéro).

Ces différentes tendances se concrétisent à la fin des années quatre-vingt par la création du département de Material Culture Studies (MCS) à l'University College de Londres (voir Buchli 2002). Ce regain d'intérêt, qui intègre alors les influences marxistes et post-structuralistes, part d'une volonté d'étudier les objets sous une perspective pluridisciplinaire et empirique, notamment par un retour à l'ethnographie et à ses méthodes, son style et ses techniques d'écriture. Dans cette optique, l'intérêt majeur des MCS se porte avant tout sur les manières dont les individus se constituent et créent un ou des mondes pour eux-mêmes, par le biais de pratiques liées 
aux objets ou aux technologies. Les usages socio-culturels et quotidiens des objets ainsi que le domaine de la consommation comme processus actif (Miller 1995, 2008 ; Sassatelli 2007 ; Slater 1997) constituent deux domaines clefs. Ce caractère pluridisciplinaire des MCS se retrouve dans le Journal of Material Culture qui depuis 1996 publie une très grande diversité d'articles sur des sujets comme la culture visuelle, la mémoire, l'architecture et l'environnement construit, l'anthropologie de l'art, la culture digitale, les paysages et la consommation.

Dans ce courant, la technologie est peu à peu délaissée au profit d'une approche de la consommation, et ce, paradoxalement, par l'affichage d'une référence aux théoriciens français. La tendance amorcée dans le volume de Douglas \& Isherwood (1979) reprise dans celui d'Appadurai (1986) et dans l'ouvrage de Miller (1995) se renforce et les MCS se revendiquent davantage de l'école historique des Annales et des représentants de la French Theory que des travaux de Mauss ou de Leroi-Gourhan sur les techniques qui restent les plus cités par la majeure partie des anthropologues des techniques.

Pourtant, l'anthropologie anglo-saxonne est familière du fait technique, et un certain nombre de textes fondateurs en abordent la complexité. Bien après l'étude classique de Blackwood, qui applique une réflexion préhistorienne au matériel ethnographique (1950), on peut repérer le fameux texte de Munn sur les pirogues de Gawa (Munn 1977) ou le volume, plus ethnoarchéologique, de Lechtman \& Merrill (1977). D'autres textes ${ }^{3}$ abordent la technique soit de manière plus directe, soit en rapport avec des sujets plus orientés vers les intérêts de leur époque, tels la question des échanges, de l'art, ou de la sexualité.

Ainsi que le déplorent plusieurs auteurs anglo-saxons, tels que Pfaffenberger (1988) ou Staudenmaier (1990), la technique demeure technology en son acception la plus limitée, et ses aspects sociaux sont principalement étudiés par les historiens ou les sociologues des sciences et des techniques, les Science \& Technology Studies. Le texte en anglais de Lemonnier, publié en 1986, dont le titre, "The Study of Material Culture Today : toward an Anthropology of Technical Systems », indique bien que l'étude des faits techniques et celle de la culture matérielle ne font qu'une, paraît avoir plus de portée en archéologie qu'en anthropologie, comme en témoigne le récent retour de l'intérêt pour les chaînes opératoires, auquel on a pu assister dans des travaux de chercheurs comme Sillar (2000, ce volume). Mais les appels en anglais des auteurs francophones, familiers avec la tradition inaugurée par Leroi-Gourhan et du laboratoire de Techniques E culture, à l'exemple de ceux de Lemonnier (1986, 1992, 1993), de Sigaut (1985, 2002 [1994]) et du travail de Schlanger à Cambridge (1990), semblent passer inaperçus chez les ethnologues britanniques. On pourrait sans doute voir dans cette situation l'une des conséquences de la spécialisation croissante des différentes disciplines dans les domaines anglophones. Les tendances transdisciplinaires pâtissent fréquemment du volume accru de publications exigées par les différents systèmes d'évaluation scientifique, ce qui oblige les chercheurs à faire des choix drastiques dans leurs listes de lecture et à citer fréquemment les auteurs phares, dont la seule mention 


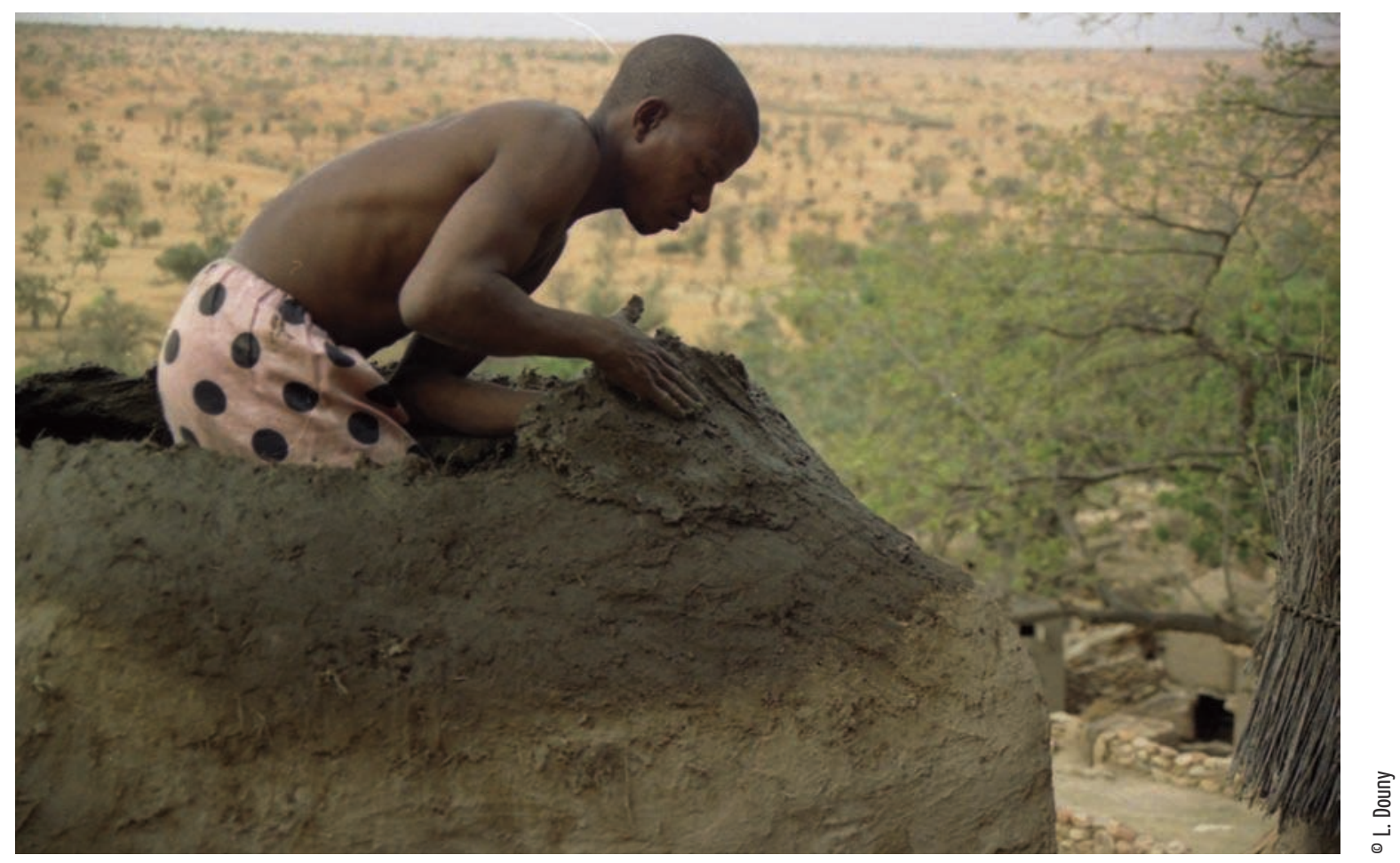

en début d'article, dans la partie théorique, permet de situer un discours ou une méthodologie en renvoyant implicitement à un corpus d'études plus profond et plus ancien mais par trop « présentifié ».

Toutefois, d'une manière peut-être surprenante, c'est dans le domaine de l'anthropologie de l'art que les techniques - ou du moins le terme technology - réapparaissent dans les approches anglo-saxonnes. Si l'ouvrage posthume de Gell, Art and agency (1998, traduit en français en 2009 sous le titre L'Art et ses agents), a connu un succès suffisant pour avoir été amplement discuté des deux côtés de la Manche, c'est davantage par deux articles, qui en sont en quelque sorte les prémices, que l'auteur évoque la possibilité d'aborder, de concert, la question des techniques et celle de l'art. Dans le plus ancien, « Technology and Magic » (1988), Gell traite des rapports entre rite, technique et esthétique, en des termes qui évoquent de façon très nette l'influence de Mauss (notamment dans son étude de la prière, 1968 [1909]) et y donne une définition de la technique qui évoque, sans la citer, celle de la chaîne opératoire fournie par Cresswell (1976), comme faisant passer un objet $x$ à un état y (Gell 1988 : 6). Puis, préfigurant L'Art et ses agents, dans un article de 1992, intitulé «Technology of Enchantment, Enchantment of Technology», qui fait partie d'un ouvrage sur l'anthropologie de l'art (Coote \& Shelton 1992), Gell jette les bases de sa vision performative des phénomènes esthétiques, qu'il distingue des approches classiques de l'esthétique, de la sémiologie et de la sociologie de l'art. Selon lui, toute œuvre d'art est issue d'un système 


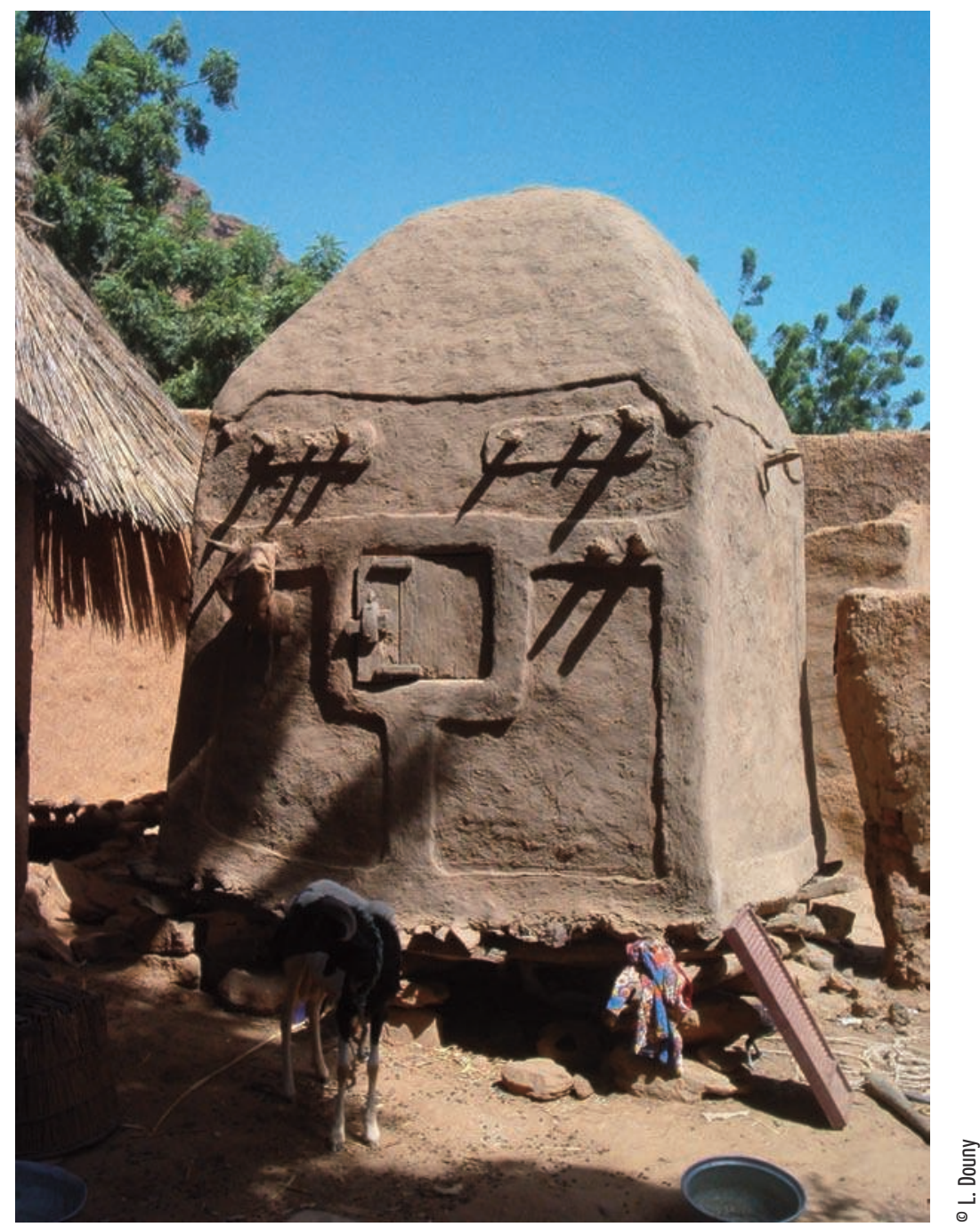

\section{Grenier femelle Dogon}

Les greniers « mâles » ou « femelles » servent principalement à contenir les semis et récoltes de céréales tels que le mil, les pois ou l'hibiscus. 
technique, dont l'opacité est à l'origine de l'effet qu'elle exerce sur nous, effet (agency) qui peut être lui-même considéré comme une technique de manipulation cognitive et sociale (voir aussi les propositions de Hirsch 1995 et Roscoe 1995).

Nous ne reviendrons pas sur la portée de l'ouvrage L'Art et ses agents, dont les propositions provocantes ont fait couler beaucoup d'encre, mais il demeure que cette conception double de la notion de technology a invité un certain nombre d'anthropologues à chercher dans les processus techniques les sources de l'effet esthétique et cognitif des objets (cf. Küchler $\&$ Were ce numéro), même si les méthodologies et les objectifs diffèrent.

Dans cette évocation générale, on ne peut pas ignorer les conséquences du fait que l'anglais est devenu langue internationale du marché du savoir et donne la priorité aux ouvrages les plus célèbres et rend par cela même un certain nombre de traditions nationales quasi invisibles. On peut toutefois ressentir les diverses influences pénétrer dans les travaux sur la technologie des collègues archéologues nord-américains, dont on ne citera que quelquesunes des publications les plus connues, comme celles de Lechtman (1977), Schiffer (1992, 2001), Dietler \& Herbich (1994) ou Pfaffenberger (1988, 1992).

Les principaux paradigmes des Material Culture Studies tels qu'ils sont présentés dans le Material Culture Reader (Buchli 2002), sont au nombre de cinq. Déjà signalé, on y retrouve l'approche marxiste et celle du structuralisme inspirées par Lévi-Strauss auxquels viennent s'ajouter la cognition, l'ethnomathématique et la phénoménologie. Nous nous arrêterons ici sur l'approche marxiste et la phénoménologie, car elles permettent d'illustrer les points de convergence et de divergence avec les traditions françaises. Premièrement, bien que l'approche marxiste, telle que nous l'avons déjà présentée, soit commune aux fondements des études sur la culture matérielle et de l'anthropologie des techniques, son apport ou son rejet diffèrent grandement. Contrairement aux approches francophones, l'approche marxiste britannique se reflète principalement dans le domaine des études de la consommation (Miller 1995), impliquant la circulation, l'échange, l'utilisation de technologies, d'objets ou de marchandises au quotidien. Deuxièmement, l'approche phénoménologique qui privilégie un engagement direct du corps dans le monde matériel, occupe une place importante dans l'étude du monde matériel notamment dans les études du paysage (Tilley 1994, 2004 ; Ingold 2000). On pressent ici que ce paradigme, enraciné dans les philosophies de Sartre, Merleau-Ponty ou Heidegger, s'instaure lui aussi en réaction contre le déconstructionisme postmoderne. L'intégration de la phénoménologie de manière générale est présente dans les travaux de Jackson (1996) qui prône un retour à l'empirisme. Ce retour se manifeste comme une volonté de recentrer la science sur le sujet.

Le terme de "matérialité » (materiality), quant à lui, correspond à une volonté affichée de focaliser le regard sur les objets et leurs caractéristiques matérielles, tout en se démarquant de manière claire d'approches «matérialistes » qui négligent les dimensions sociales du rapport aux artefacts ou, pire, les laissent dans leur boîte noire. Le terme est peu spécifique, à tel point que Miller joue avec les différentes dimensions conceptuelles 
et théoriques du terme afin d'en esquisser l'importance pour la fondation d'une «théorie des choses » (a theory of things ; Miller 2005 : 4). En recourant à Bourdieu, Gell, Hegel ou Gombrich, Miller fait preuve de la même tendance qui traverse l'anthropologie et qui rejette les vieux dualismes, ici matériel/immatériel, structure/pratique. Pour ce faire, il refuse de restreindre le terme à une définition qui en atténuerait la pertinence, et le laisse presque au stade de "signifiant heuristique flottant», dont les contours n'apparaissent qu'au cas par cas.

Toutefois, nous pouvons préciser ici ce que le recours au terme « matérialité » signifie du point de vue de la méthode. Si l'on considère la manière dont le terme sociality est venu souligner la dimension relationnelle du concept de « société » (cf. Strathern 1991), materiality mettrait alors l'accent sur les propriétés relationnelles de material (compris ici à la fois comme « matériel » et «matériaux »). Traduite en français, « la matérialité » serait alors l'ensemble des propriétés phénoménales et matérielles des « choses», ensemble conçu comme forme de potentiel ou de " possibles », qui serait perceptible lors de son utilisation physique et/ou conceptuelle (en anglais engagement). Cette idée de matérialité serait alors utile pour éviter de retomber dans les vieux dualismes tout en accordant aux objets la capacité de résoudre l'oxymore que semble contenir le terme "culture matérielle", où « culture » renverrait au domaine du conventionnel et de l'arbitraire et « matériel » renverrait à des déterminismes universels. Si le caractère évocateur mais flou du terme «materiality » permet une grande souplesse d'utilisation, il ne convainc pas l'anthropologue Ingold (2007) pour qui il s'agit d'une sorte de dérive théorique qui met l'accent sur une approche trop métaphysique des objets au détriment des aspects justement physiques, matériels, et entre autres, techniques. Autrement dit, ce qu'il manque à cette notion serait justement l'attention portée à la pratique technique, aux processus de transformation des matériaux et de la manière dont ces processus sont en prise avec les modes de pensée et d'être de ceux qui les pratiquent. Ce à quoi renvoient généralement les approches francophones.

\section{France : La technologie est la culture matérielle}

Du côté francophone, le chemin parcouru en technologie culturelle nous mène de Mauss à Lemonnier, en passant par Leroi-Gourhan, Haudricourt et Cresswell. Ici, l'étude des techniques coinncide avec l'étude de la culture matérielle en prise avec le corps (Mauss 1950 [1935]), et s'étudie dans les gestes, la parole et les rythmes (cf. Leroi-Gourhan 1964'). Elle se nourrit de l'anthropologie marxiste et de son intérêt pour les forces de production, faisant émerger les notions d'efficacité, de rapports entre techniques et sociétés et de tâches stratégiques. Elle perfectionne l'outil méthodologique que constitue la " chaîne opératoire » et crée le terme de «technologie culturelle ». Profondément inscrite dans une tradition ethnographique 
et empirique, l'étude de la culture matérielle en France se penche sur les variations des cultures techniques. L'étude des techniques comme fait social se retrouve héritière de tendances dont les multiples directions théoriques et méthodologiques ont parfois brouillé les dialogues avec les autres disciplines, mais ont défini un ensemble de questions fondamentales. Au risque de paraître schématique, nous distinguerons quatre de ces tendances entremêlées, dont les noms (Leroi-Gourhan, Haudricourt, Rivière, Cresswell) et les parcours s'entrecroisent : muséologique, ethnographique, anthropologique et l'étude préhistorique et archéologique de la culture matérielle.

En effet, après Mauss, l'approche française trouve ses sources dans l'anthropologie comparative et muséale de Leroi-Gourhan, approche que l'on peut estimer au fondement de plusieurs directions de recherche, tant d'un point de vue historique que disciplinaire ou méthodologique. Le travail minutieux effectué au musée de l'Homme, qui donnera naissance aux deux volumes, inconnus dans le monde anglo-saxon d'Évolution et Techniques (1971 [1943] et 1973 [1945]), sera la référence principale, tant pour sa précision empirique que pour les éléments de réflexion théorique qu'il propose. Les notions de tendance et de fait technique, de même que celle d'action élémentaire sur la matière, offrent un mode de classification des techniques alternatif aux modèles évolutionnistes, diffusionnistes ou fonctionnalistes.

C'est à partir de cette position centrale que vont émerger, par la création du CRFE (Centre de Formation aux Recherches Ethnologiques), en 1946, trois nouvelles directions. L'une d'entre elles peut être qualifiée comme étant la « branche » préhistorique ou paléoethnographique, où l'on voit se côtoyer les différentes générations du chantier école de Pincevent (archéozoologues, technologues ou ethnoarchéologues notamment). La seconde, plus proche de l'ethnographie française, prolonge l'expérience muséale de la galerie d'étude du musée des Arts et Traditions populaires. Enfin, la troisième, est celle de Techniques et culture des années soixante-dix, plus matérialiste et politique dans ses fondements.

Ces trois tendances trouvent dans l'étude des systèmes techniques et dans l'outil méthodologique offert par la chaîne opératoire, un appareil empirique adéquat pour analyser, dans le détail, la dimension culturelle (donc, relative), sociale (donc potentiellement construite), évolutive (donc historique) et fonctionnelle (ethnologique) de la vie matérielle.

En même temps, on retrouve cet intérêt pour la culture matérielle dans une ethnographie de la France encore profondément ancrée dans les musées (Segalen 2005), en relation avec la personnalité de Georges-Henri Rivière, dont les travaux vont largement influencer le développement des musées et de la muséologie (Chiva 1985). Toutefois, si cette orientation profite de la documentation des pratiques régionales et des débuts des écomusées, elle ne parvient pas complètement à profiter du succès croissant des industries du patrimoine et des processus de « muséification ». Louverture en 1972 de la Galerie d'étude du musée des Arts et Traditions populaires prolonge logiquement les recherches menées dans l'après-guerre par le 


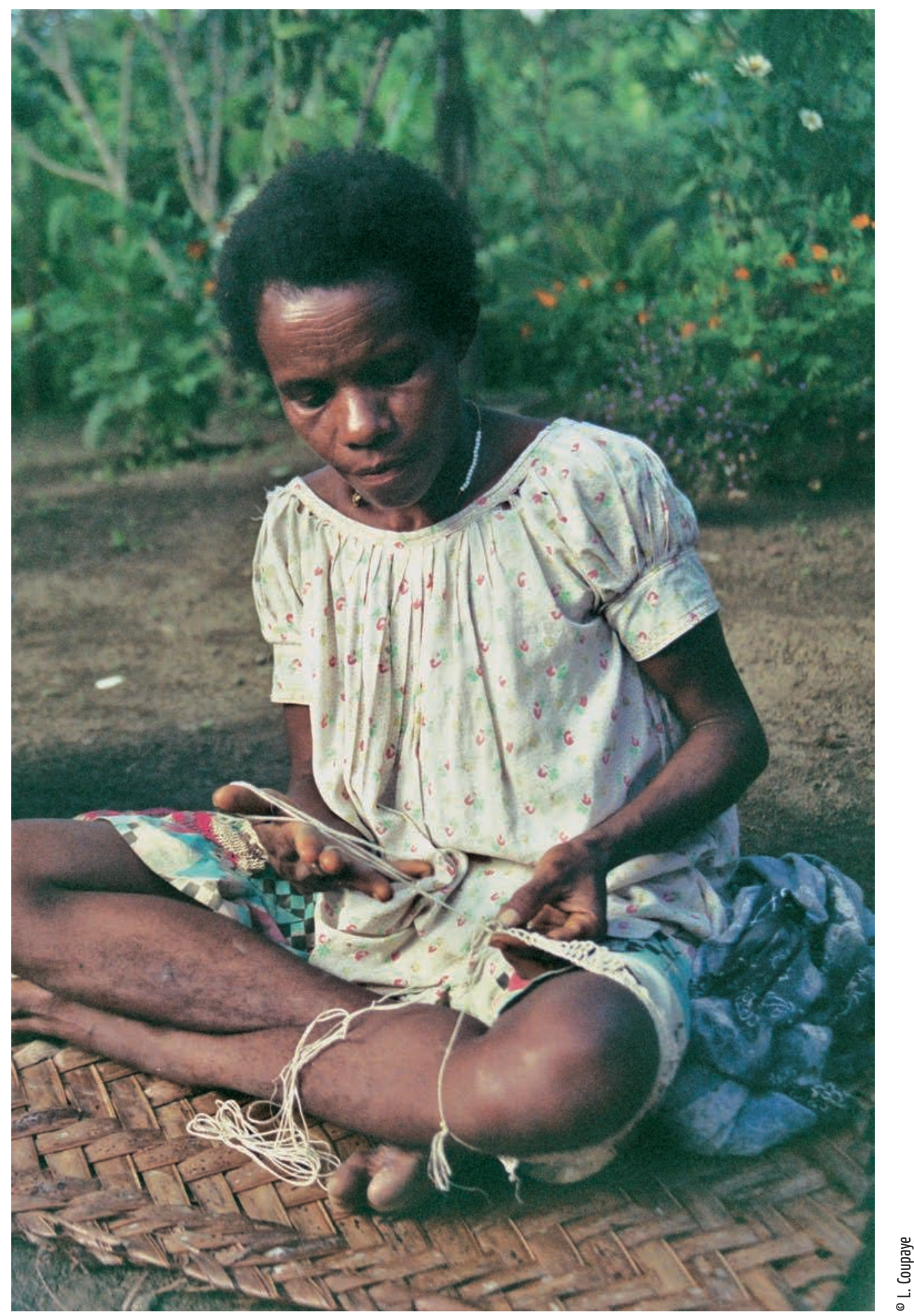


CFRE (Bromberger \& al. 1986). La faible fréquentation du musée national des Arts et Traditions populaires ne lui permet cependant pas de constituer une « vitrine publique » de ce type de recherches.

Du côté du CNRS et de l'anthropologie « lointaine » des techniques, l'influence théorique marxiste semble éloigner l'étude des techniques du domaine des objets de musée, comme s'il était trop étroit, pour aborder, via l'analyse des moyens de production, la production du social et de ses bases matérielles (Godelier 1969 ; Godelier \& Garanger 1973). La création en 1974 de l'équipe de recherche (ER) 191 « Techniques et culture », qui conduit à la création de la présente revue, va permettre de présenter, côte à côte, les recherches sur les techniques horticoles de Nouvelle-Guinée, celles sur les forges irlandaises ou sur le machinisme. Aux côtés des textes des anthropologues français comme Cresswell, Mahias, Sigaut ou Lemonnier, on y voit publier des auteurs anglo-saxons plus connus, tels que Bray ( $\left.n^{\circ} 11,1988\right)$, Ingold ( $\left.{ }^{\circ} 12,1989\right)$, Pfaffenberger (n 16, 1990) ou encore Van der Leeuw (Van der Leeuw n 17-18, 1992 ; Papousek \& Coudart 1992). On y traite d'écomusées, d'archéologie, de techniques industrielles modernes, d'ingénierie, ou d'innovation. L'ethnologie et la préhistoire y côtoient l'ethnoarchéologie, la sociologie des sciences ou la linguistique. L'étude des techniques reste délibérément empiriste, mais en parcourant les sommaires de Techniques $\varepsilon$ culture des années quatre-vingt, on y décèle non seulement des questions et des problématiques récurrentes au domaine (la dimension sociale des techniques, l'innovation, l'efficacité), mais aussi des thèmes qui sont aujourd'hui au cour de l'anthropologie internationale, comme le genre, le corps, le développement, ou encore, les dimensions cognitives des techniques.

En parallèle, et loin de la tendance marxiste et des méthodologies classiques de la technologie culturelle, se développe l'approche praxéologique que nous avons mentionnée plus haut (Warnier 1999 ; Julien \& Warnier 1999 ; Julien \& al. 2003 ; Julien \& Rosselin 2005) qui aura plus de succès chez les Britanniques. Ce développement est dû notamment à la longue amitié et collaboration entre Warnier et Rowlands, qui avaient déjà effectué par le passé des recherches en relation avec le domaine des techniques (Rowlands \& Warnier 1995). La praxéologie développée par le groupe Matière à penser s'oriente vers l'exploration du monde matériel et de sa matérialité par l'action « située » dite sensori-motrice (Parlebas 1999), c'està-dire résultant de processus intersubjectifs d'apprentissage de techniques, acquis lors de pratiques qui, selon Jean-Pierre Warnier, sont enracinées dans le sujet. Ainsi développée par Warnier et son équipe, la praxéologie prend origine dans les techniques du corps (1936) de Mauss et dans les techniques du soi de Foucault (1989). Dès lors, cette méthode affirme que lorsque le corps façonne ou transforme l'objet, l'objet, à son tour, façonne le corps. On peut souligner que cette approche réciproque de la matérialité et du corps correspond à celles des études sur la culture matérielle. Dans cette perspective, la praxéologie devient encore plus intéressante pour l'étude des styles de vie, de l'organisation du quotidien, de la conception de l'espace et du temps, de la transmission des connaissances techniques et symboliques et enfin du savoir-faire.
Sur la photo de la page opposée, Roselyne Gubisge prépare un filet de portage, bilum en Tok Pisin (wut en Abulës) lors d'une session d'apprentissage. La main gauche maintient le filet, tandis que la main droite enroule le fil pour le tirer au travers du nœud dans lequel il a été passé.

Maureen Mackenzie (1991) a étudié avec précision les chaînes opératoires de fabrication des bilum dans les Hautes Terres de PapouasieNouvelle-Guinée, montrant la manière dont ces objets acquièrent au cours de leur fabrication une nature, tout à la fois masculine et féminine. (Photo : Nyamikum, ESP, PNG, 06.03.2003). 


\section{Tournant pluridisciplinaire et symétrisation}

À la fin des années quatre-vingt, l'émergence des STS (Sciences and Technology Studies) en France semble annoncer un tournant interdisciplinaire, notamment au cours d'un colloque organisé à propos de l'intelligence sociale des techniques. Le résultat de cette rencontre est publié dans le volume De la Préhistoire aux missiles balistiques (Latour \& Lemonnier 1994) que l'on peut qualifier d'un moment fort de cristallisation de différents courants d'analyse de la matérialité. Le texte introductif de Latour et Lemonnier donne une image nette des enjeux des études sur la technologie en France au début des années quatre-vingt-dix. Cette image est une sorte d'instantané ou de « sondage »comme pourraient le dire les archéologues - à travers les différentes disciplines qui s'intéressent aux faits techniques. Anthropologues, éthologues, économistes, philosophes, archéologues, historiens et sociologues en constituent les principaux interlocuteurs et illustrent au cœur du volume la variété des questions, des méthodologies et des fondements théoriques qui surgissent dès que l'on parle des techniques. Parcourant aujourd'hui ce volume, on y voit émerger des thèmes majeurs de l'anthropologie actuelle, tels la cognition, le sujet et la construction réciproque des personnes et des objets, la modernité, le genre, le corps, la nature, la porosité des frontières humains-non-humains (Joulian 1994; Strum 1994).

De cet ouvrage collectif, il ne manque que les questions numériques et Internet ou celles liées aux problèmes légaux liés à la circulation des images et du son. L'autre grand absent, étrangement écarté du champ de ce type de recherches, est le musée. Pris dans la spirale du renouveau qui présage de ce qui sera au cœur des débats à propos de la rénovation du musée de l'Homme, de la création du musée du Quai Branly ou du devenir du musée des Arts et Traditions populaires, le champ des techniques subit les conséquences d'un autre dualisme, qui entérine la division institutionnelle entre objet ethnographique et objet d'art. Par ailleurs, le divorce entre musée et anthropologie, dont parlait Sturtevant, a eu lieu aussi en France. La «fièvre des musées » s'effectue sans les anthropologues, qui s'en sont écartés trop tôt et tenteront trop tard d'y participer d'une manière qui les satisfasse, comme l'illustrent les débats autour de l'ouverture du musée du Quai Branly.

Rétrospectivement, De la Préhistoire aux missiles balistiques reflète de la manière la plus éclatante qui soit le caractère profondément transversal du sujet. Étudier la technique c'est frotter les disciplines les unes contre les autres, comme le montre parfaitement l'orientation actuelle de Techniques \& culture. On aurait même pu en effet espérer que puisse naître d'un tel constat cette fameuse « technologie, science humaine » proposée par Haudricourt (1987). Cette introduction attaque donc de plein front les vieux problèmes inhérents à l'étude des techniques : la persistance des dualismes et des débats sur les déterminismes y est déployée et rejetée au profit d’une approche où on ne peut s'empêcher de voir dominer l'influence sociologique et des thèmes chers aux latouriens : la notion de collectifs, l'hétérogénéité des réseaux et l'étude des processus d'innovation. 


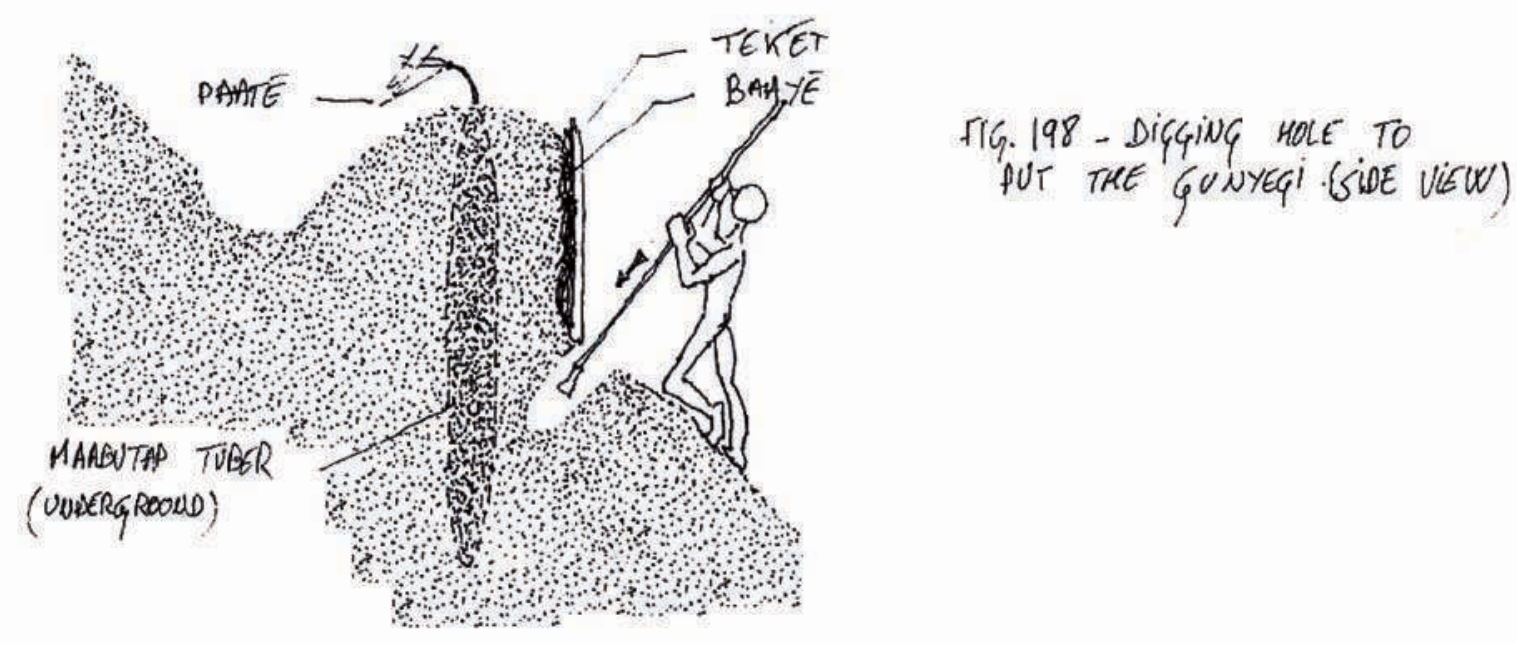

Mais au final, on peut également dire que le dialogue entre la nouvelle sociologie des sciences et des techniques et l'anthropologie reste difficile, tant les modèles de scientificité inhérents aux deux courants diffèrent.

\section{La question des déterminismes?}

Si l'on nous pardonne un raccourci un peu audacieux, il se pourrait que ce soit autour de la question du déterminisme, qu'ils soit évolutionniste, diffusionniste ou marxiste, que se situe l'articulation signifiante entre anthropologie, sociologie, approches francophones et approches anglophones. On peut en effet considérer que c'est cette même question qui permet à l'approche sociologique de prendre une place privilégiée, presque rédemptrice, au tournant des années quatre-vingt, quatre-vingt-dix. Lorsque Latour et Lemonnier écrivent : « curieusement, les chercheurs qui travaillent sur les techniques de pointe insistent davantage sur l'impossibilité de les séparer du monde social ou de les juger à la seule aune de l'efficacité, que ceux qui étudient les herminettes, les silex ou les faux » (Latour \& Lemonnier 1994: 17), une séparation - on pourrait même dire une « purification »-s'opère entre l'étude des techniques de pointe et les « prémodernes ». Ceci annonce également un point de rupture crucial entre les deux approches, tel qu'il se matérialisera peu de temps après à propos de l'efficacité dans le débat entre Lemonnier et Latour dans L'Ethnologie Française (Lemonnier 1996 ; Latour 1996).

On assiste alors à un échange dont, au-delà de la possible méprise des intentions, on pourrait croire qu'il s'agit effectivement de savoir si l'on doit d'abord distinguer la dimension physique de la dimension sociale des techniques avant de les réassocier, ou s'il le faut, à l'inverse, accepter de penser dès le départ cette « hybridité » des faits socio-techniques. Pour la

Croquis de terrain

montrant un homme creusant un tunnel afin d'atteindre l'extrémité inférieure d'une grande igname enfouie sous son monticule. Placé en contrebas du monticule, l'homme utilise un outil fait d'un long manche de bois au bout duquel est fixée l'extrémité aiguisée de la lame d'une machette. Progressant avec prudence, afin de ne pas risquer d'endommager le tubercule, le cultivateur va créer un accès qui va lui permettre d'administrer à la pointe de l'igname des substances « magiques », aussi appelées des « fertilisants », composées à partir d'une recette tenue secrète et dont il est le propriétaire. Ces substances, en partie acquises par échanges, en parties recueillies dans des endroits précis du territoire, dont certains sont associés aux entités totémiques du clan du cultivateur, sont censées " exciter » le tubercule, le nourrir et l'inviter à descendre plus bas - donc à atteindre une plus grande taille. (Dessin : L. Coupaye, d'après une session de travail avec Kony Gambakiya du 16.04.2003, carnet de techniques II, p.152). 
technologie culturelle, cette distinction est d'ordre méthodologique. Elle se méfie du seamless web, le «tissu sans couture » (Hughes 1969), que les chercheurs des Sciences and Technology Studies promeuvent dans leurs recherches (cf. Cresswell 1993 : 18). Pour la sociologie des techniques et de l'innovation, cette distinction, faite a priori, présente le risque de reproduire les vieux dualismes sous de nouvelles formes (Latour 1992).

Il y a plusieurs façons d'interpréter ce débat. Ce que nous proposons ici est une lecture qui permet de souligner les points communs avec l'attitude des Britanniques vis-à-vis de la technique. Un certain nombre d'auteurs ont déjà exploré la question des différences de méthode et d'échelle d'analyse (cf. Cohen \& Pestre 1998 ; Geslin 2002 ; Cresswell 2003). Mais plutôt que d'insister sur les différences, nous avancerons l'idée que si les enjeux ne sont pas tout à fait identiques ou qu'ils ont des points d'origine distincts, ils sont suffisamment proches pour qu'on s'entende sur le fond. La technologie culturelle s'appuie sur une tradition qui tente de re-humaniser les faits techniques, ici comme là-bas, en apparence piétinés par un discours dominant, qui, au nom du progrès industriel, a construit son projet colonial en lien avec une volonté de faire évoluer l'environnement technique des «primitifs». La nouvelle sociologie des sciences et des techniques contient également une critique de la notion de progrès linéaire, mais veut quant à elle montrer l'enchevêtrement de la modernité et démontrer in fine que la rationalité qui la sous-tend est tout aussi locale que celle des prémodernes.

Bien que ces deux positions se cristallisent autour de l'importance donnée, soit à l'efficacité, soit à l'hybridité, leur mise en relation éclaire un point central, qui peut permettre de comprendre les différences, les incompréhensions et peut-être les points communs entre les approches françaises et les approches britanniques (on notera ici les pluriels utilisés sur les deux adjectifs). En effet, s'il est un point que l'on peut dégager de ces débats, c'est la critique des vieux modèles explicatifs essentialistes ou linéaires, et l'idée qu'il faut se méfier des déterminismes simples.

\section{Le déterminisme en question}

On pourrait d'abord croire, comme le signale Latour dans sa réponse au texte de Lemonnier (1996) que ce qui les oppose n'est qu'une des multiples ombres projetées du dualisme fonction/style, pourtant déjà attaqué dans leur introduction à La Préhistoire aux missiles balistiques. On aurait, d'un côté, une prise en compte des dimensions déterminantes de l'universalité des lois physiques (de la matière, du temps et de l'espace), en relation avec le champ du social et de ses représentations, et, de l'autre, un intérêt plus porté aux valeurs négociées, fluctuantes, complexes, relationnelles, et en définitive, construites. Cela n'est pas sans évoquer - tout en s'en démarquant - les analyses herméneutiques postmodernes. 
Si l'on étend la réflexion hors des cercles académiques et des frontières linguistiques anglo-françaises, force est de constater que ce dualisme est probablement toujours d'actualité. Par un effet de contagion et de vulgarisation, le terme de «technologie », comme le rappelle Sigaut (1985, 2002 [1994], ce volume), surtout aux États-Unis et en Angleterre, mais aussi en France, reste plus que jamais inséparable des productions occidentales « modernes », « de pointe » ou « nouvelles », notamment quand il s'agit de biotechnologie, d'informatique, du digital ou de la téléphonie mobile. Même si ces domaines font l'objet de débats publics, et même si on explore les risques, directs ou indirects qu'ils font courir, leur mode d'existence, le progrès technique, n'est pas questionné de la même façon qu'en anthropologie ou en sociologie.

Si les projets (ethnologique chez Lemonnier, ou socio-philosophique chez Latour) diffèrent, ils éclairent pourtant un point d'articulation essentiel, illustré par leurs discussions sur la notion d'efficacité, mais qui fait aussi écho à des débats antérieurs sur le déterminisme. En effet, l'étude des notions d'efficacité (sociale des techniques ou technique des sociétés) et de tendance technique pose implicitement la question des déterminants des faits observés, qu'ils soient techniques, sociaux, culturels ou historiques. En d'autres termes, l'étude de l'efficacité des techniques jugées " primitives » repose sur des termes empiriques, matériels, donc jugés plus heuristiques (ce dont témoigne la question de la rationalité indigène qui a traversé l'histoire de l'anthropologie de Frazer à Descola). Les techniques « primitives » (ou traditionnelles, dans le cas des techniques artisanales « proches » qui ont survécu à l'industrialisation) ont tout autant droit de cité que celles du monde moderne. En cherchant les fondements de l'efficacité du rituel et sa justification sociale ou culturelle profonde ou en montrant que les « aberrations » comportementales constatées dans les systèmes techniques, tels que la plantation des ignames, la fabrication des clôtures ou la cuisson de la poterie, possèdent cette fameuse efficacité définie par Mauss, on peut implicitement revaloriser ce que deux à quatre siècles de colonisation et d'industrialisation ont constamment tenté d'éradiquer. Du même coup, on critique la domination idéologique occidentale.

En revanche, la démarche latourienne part d'un point de vue opposé. En démontrant que des processus modernes proches (qui se manifestent dans nos assiettes, nos corps et nos institutions politiques) et jugés des plus rationnels (tels que la technologie des transports, l'organisation d'un clavier d'ordinateur ou l'élaboration du droit) sont tout autant soumis à des formes d'irrationalités, de rituels, de croyances, de discours que ne le sont celles des populations « pré-modernes », cette démarche entreprend aussi une critique de l'ethnocentrisme de la pensée occidentale qui, ces derniers siècles, s'est répandue sur toute la planète au point qu'elle semble risquer de la détruire.

Partant de deux extrémités opposées (le lointain et le proche), ces deux démarches se rejoignent pour remettre en question la domination de certaines formes de déterminismes sous-jacents à la pensée techno-scientifique occidentale. Tout se passe maintenant comme si l'on cherchait à trouver de l'efficacité dans ce qui était jugé irrationnel 
et de l'irrationnel dans ce qui était jugé efficace. Mais au-delà de cette ambivalence, on retrouve le même combat contre des déterminismes unilinéaires et surtout contre les déterminismes matériels sur lesquels semble fondée la pensée rationnelle occidentale ; pensée qui bien qu'elle soit battue en brèche dans l'enceinte académique reste très largement dominante dans la sphère publique et politique ${ }^{6}$.

\section{Repenser les déterminismes}

Il ne s'agit pas, bien sûr, de réduire la question anthropologique des techniques, ni d'ailleurs celle des différences de traditions, à cette simple question du déterminisme. Nous avons choisi cet angle d'approche afin de pouvoir résumer de manière brève ces différentes trajectoires puis de tenter de définir l'un des points centraux sur lesquelles elles se rejoignent, ne serait-ce que pour en débattre. Il est possible que l'attitude qui consiste à rejeter le bébé technologique avec l'eau du bain déterministe, que l'on ressent fortement dans les approches britanniques (cf. Küchler $\&$ Were, ce numéro, et Miller, ce numéro), s'appuie sur le même refus de la vision trop linéaire qui a marqué les études de la culture matérielle anglo-saxonne de Rivers à White. Il est aussi possible que l'on puisse sentir dans le recours au langage académique foucaldien un souci équivalent d'éviter les impasses des déterminismes, matériels ou sociaux, ceux-là même qui ont fait que la technologie et l'étude des processus techniques n'intéressent guère les anthropologues britanniques.

Ce point commun sous-tend toute une série d'idées reçues - à la source du fameux caractère « invisible » ou de « boîte noire » (Lemonnier 1996 : 545 ; Pfaffenberger 1992 : 200-502 ; Sigaut 2002 : 451) - sur la place des techniques et de leurs objets au sein des sociétés et de leur rapport au temps (progrès) et à l'espace (l'environnement, ses ressources et ses contraintes). Les techniques semblent d'autant plus difficiles à aborder d'un point de vue anthropologique que ce qui les gouverne se situe fréquemment dans l'espace laissé vacant par la vielle division entre Geisteswissenschaften et Naturwissenschaften. Cet espace est, comme le suggérait Latour, souvent celui où prolifèrent les hybrides, qu'il s'agisse de rituels créateurs de sens et recourant à des objets, d'« existants » transformés par des intentions, de corps transfigurés, génétiquement manipulés ou de paysages « patrimonialisés ».

Cette position entre deux pôles épistémiques est peut-être à l'origine de la méfiance contemporaine anglo-saxonne. Comme si le simple fait d'avoir à traiter des lois de la matière ou de la notion d'efficacité risquerait de nier la contingence, l'inventivité ou la stratégie des personnes impliquées dans les processus. La raison est peut-être liée aux penchants marxistes des premiers temps et à une vision trop étroitement « économiste » qui en découle ou encore à la focalisation sur le caractère utilitaire des techniques au détriment de leurs dimensions plus « symboliques» (cf. Warnier 2009: 461 ; Sigaut, 
ce numéro). En comparaison, les études sociologiques sur l'innovation pouvaient constituer non seulement un point d'entrée privilégié, historiquement pertinent (étant donné, comme on l'a vu, l'ancienneté du sujet, y compris dans les approches historiques) mais aussi peut-être plus facile à aborder du point de vue théorique, sans avoir à traiter de plein front cette question des déterminismes, après tout, source d'embarras (Ucko 1969).

La volonté d'échapper à un matérialisme primaire, trop associé à une « vulgate marxiste » a pu inciter une majorité d'anthropologues anglophones à insister davantage sur les discours et les représentations. L'enjeu, comme chez les sociologues, semble être ici aussi de remettre en question la fausse concrétude de Whitehead (1925: 72) - du fait technique et/ou de ses résultats. En contrebalançant une approche jugée trop matérialiste par une approche des objets en tant que signes (Keane 2005) ou en tant que résultats de réseaux de nature hétérogène, d'autres voies d'analyse se présentent sur le marché actuel. Par ailleurs, la notion de " matérialité ", mise en avant par l'anthropologie de la culture matérielle britannique (bien que controversée, Ingold 2007) a eu le mérite de briser le carcan positiviste des approches anthropologiques classiques, qui avaient en définitive elles aussi implicitement validé une vision déterministe, en ignorant la dimension sociale des techniques. Cette situation contraste bien entendu avec l'approche française, qui, elle, bénéficie de la perspective ouverte par les travaux de Mauss et de Leroi-Gourhan, non traduits, ou très tardivement.

À ce jour, il existe un certain nombre d'issues possibles, permettant d'échapper à la vieille habitude positiviste qui voit dans l'étude des techniques ou de la technologie (technology) le risque de pactiser avec les penchants déterministes ou causalistes. En découplant, comme le suggère Sigaut (2002b), l'efficacité et l'utilité, on peut en effet retrouver la manière dont les intentionnalités et les systèmes d'inférences gouvernent et donnent leurs sens non seulement aux actions sur la matière elle-même, mais aussi aux opérations choisies pour transformer cette dernière.

Comme nous l'avons décrit dans ce bref aperçu de la technologie au sein de la culture matérielle dans le milieu anglo-saxon, il semblerait que l'émergence de concepts tels que ceux d'empathie, d'affordance, d'intersubjectivité ou encore d'approches comme celles de la phénoménologie et de la praxéologie correspondent à des tentatives de réinstaurer l'action et ses effets sur le sujet, la société, le corps et la matière, ce qui est par ailleurs au cœur des préoccupations des sciences sociales. Ces approches correspondent à la tentative anglophone de contrer l'ultra relativisme issu de la période déconstructionniste postmoderne tout en conservant certains de ses acquis, notamment en matière de réintroduction du sujet au cœur du débat post-durkemien de la distinction individu/société. Ainsi, même si fondamentalement distinctes de l'importance française données aux actions sur la matière, les approches britanniques des « choses » correspondent au même souci de réintroduire l'action des corps et du sujet au sein de l'analyse.

Ces questions émergeantes (ou re-émergeantes) de l'affordance (Naji), cette articulation entre promesse et permission, cette « empathie avec la matière » (Küchler \& Were) empruntent prudemment aux approches 
cognitivistes ; celle des savoir-faire et des compétences d'Ingold (2002) ouvrent d'autres voies d'analyse, dès lors que l'on considère aussi les contraintes de la matière en relation avec les activités. Du coup, la première question anthropologique pourrait, en définitive, ne pas être « quel rôle ces contraintes objectives ou matérielles jouent sur les processus » mais plutôt « quelles sont les contraintes perçues, inférées, contournées et interprétées par ceux-là mêmes qui font les choses ». Il s'agit alors peut-être de compléter les interprétations des pratiques par les descriptions, comme celles fournies, entre autres, par la chaîne opératoire et peut-être suivre, comme nous le recommande Wittgenstein (1993 [1922]) ou Glock (2002 : 108-115) les nécessités logiques propres à ceux dont nous parlons, plutôt que de rechercher les causes des actions techniques.

Les articles présentés dans ce Thema sont le résultat de rencontres de trajectoires, et les auteurs, essentiellement britanniques, ont bien voulu se prêter au jeu de nous présenter leurs propres utilisations du terme «technologie ». Que leurs définitions et utilisations du terme ne soient pas les mêmes que celles auxquelles les contributeurs à cette revue nous ont habitués importe tout compte fait moins que les cheminements et les réflexions que la notion de technologie a générés au sein des études contemporaines de la matérialité.

\section{NOTES}

Image d'ouverture : Michael Nyagambi, sculpteur du village de Nyamikum (province du Sepik Oriental, Papouasie-Nouvelle-Guinée), réalise une figure de calao (paal). Cette figure est faite à partir d'une planche qui provient de la racine aérienne d'une essence d'arbre appelée Saalgi en langue locale. Une fois finies, ces figures, généralement préparées pour l'ouverture d'une maison cérémonielle, sont peintes et exposées sur la façade. Après un dessin préparatoire au charbon, Kelus Nyagambi, le fils de Michael détoure la figure en utilisant une machette tenue à mi-lame, avant que la finition à l'herminette ne soit entamée par son père. La figure ne sera pas achevée: la planche va se fendre au niveau du pied. Michael interprétera cet échec comme venant des tensions très fortes pesant sur l'ensemble du village depuis plusieurs mois : conflits territoriaux avec l'un des villages voisins, disputes fréquentes, décès multiples.

1. Ce numéro, ainsi que le numéro 14 (4) du Journal of Material Culture, émanent de quatre journées universitaires, la première à Norwich, en 2005, la seconde à UCL, Londres, en janvier 2008, la troisième au SHADYC à la Vieille Charité de Marseille, un an plus tard, en janvier 2009 (cf. Naji \& Douny 2009) et la dernière, en mars 2009, à l'université de Provence.
2. $c f$. Le projet « England: The Other Within », du Pitt-Rivers Museum, http://england.prm.ox.ac.uk/ englishness-anthropology-and-technology.html.

3. On citera, parmi d'autres, Forge (1962), Damon (1980), Sillitoe (1988), Mackenzie (1991), Gell (1988, 1992), J. Wiener (1995), Barlow et Lipset (1997), J. Leach (2002) ou de Campbell (2002).

4. Voir notamment Ingold 1999 pour une discussion en anglais. Jusqu'alors, la majeure partie des anthropologues anglophones ne connaissaient, de LeroiGourhan, que son essai structuraliste de l'art préhistorique (Leroi-Gourhan 1967).

5. Selon l'expression de Michel Guérin et d'Emmanuel de Roux, dans un article du journal Le Monde, du 2 février 1993, «La Fièvre des musée - Les nouveaux temples de la consommation culturelle » qui confirme le mouvement de renouveau muséal en France, dans la suite des grands chantiers présidentiels, dont un des derniers avatars est le musée du Quai Branly ainsi que les débats qui entourent sa création.

6. Cette critique peut être, probablement, considérée de pair avec la volonté d'échapper à la montée d'une forme très conservatrice de scientisme qui semble s'accompagner de la professionnalisation des disciplines et de leurs pratiques (cf. Joulian \& de Cheveigné 2008). 


\section{RÉFÉRENCES}

Appadurai, Arjun, 1986, «Introduction : Commodities and the Politics of Value », in The Social Life of Things : Commodities in Cultural Perspective, Arjun Appadurai ed., Cambridge, Cambridge University Press : 3-63.

Barlow, Kathleen \& David Lipset, 1997, « Dialogics of Material Culture : Male and Female in Murik Outrigger Canoes », American Ethnologist, 24 (1) : 4-36.

Barth, Fredrik, André Gingrich, Robert Parkin \& Sydel Silverman, 2005, One Discipline, Four Ways : British, German, French and American Anthropology, The Halle Lectures. Chicago \& Londres, University of Chicago Press.

Baudrillard, Jean, 1968, Le Système des Objets. Paris, Gallimard.

Baudrillard, Jean, 1973, Le Miroir de la production ou l'Illusion critique du matérialisme historique. Paris, Casterman.

Bijsker, Wieve, Thomas Hugues \& Trevor Pinch eds., 1987, The Social Construction of Technological Systems: New Directions in the Sociology and History of Technology. Cambridge (Mass.), MIT Press.

Blackwood, Beatrice, 1950, The Technology of a Modern Stone Age People in New Guinea. Occasional Papers on Technology 3. Oxford, Pitt Rivers Museum of Oxford.

Bray, Francesca, 1988, "Conditions of Production and the Differenciation of the Peasantry in Rice Economy », Techniques \& Culture n $11: 15-39$.

Bromberger, Christian \& al., 1986, « Hommage à André Leroi-Gourhan », Terrain nº 7 : 61-76.

Bromberger, Christian \& Denis Chevallier eds., 1999, Carrières d'objets. Paris, Éditions de la Maison des sciences de l'homme.

Buchli, Victor ed., 2002, The Material Culture Reader. Oxford \& New York, Berg.

Campbell, Shirley F., 2002, The Art of Kula. Oxford, Berg.

Chevalier, Sophie, 1998, « From Woolen Carpet to Grass Carpet : Bridging House and Garden in an English Suburb », in Daniel Miller ed., Material Cultures: Why Some Things Matter. Chicago, The University of Chicago Press : 47-71.

Chiva, Isac, 1985, « George-Henri Rivière : un demi-siècle d'ethnologie de la France », Terrain nº 5 : 76-83.

Cohen, Yves \& Dominique Pestre, 1998, « Présentation », Annales. Histoire, Sciences Sociales, 53 (4) : 721-744.

Coote, Jeremy \& Anthony Shelton eds., 1992, Anthropology, Art and Aesthetics. Oxford, Clarendon Press.

Cresswell, Robert, 1976, "Techniques et Culture. Les bases d'un programme de travail », Techniques \& culture, Bulletin no 1 de l'ER 191.

Cresswell, Robert, 1993, Prométhée ou Pandore? Propos de technologie culturelle. Paris, Kimé.

Cresswell, Robert, 2003, « Geste technique, fait social total. Le technique est-il dans le social ou face à lui ?», Techniques \& culture [En ligne], 40 | 2003, mis en ligne le 11 juillet 2006, Consulté le 11 mai 2010. <URL : http://tc.revues.org/1576>.

Cusset, François, 2003, French Theory: Foucault, Derrida, Deleuze \& Cie et les mutations de la vie intellectuelle aux États-Unis. Paris, La Découverte.

Damon, Frederick H., 1980, «The Kula and Generalised Exchange: Considering Some Unconsidered Aspects of the Elementary Structures of Kinship », Man, New Series 15 (2) : 262-92.

Dietler Michael \& Herbich Ingrid, 1994, « Habitus et reproduction sociale des techniques. L'intelligence du style en archéologie et en ethno-archéologie », in Bruno Latour \& Lemonnier Pierre eds., De la Préhistoire aux missiles balistiques. L’intelligence sociale des techniques. Paris, La Découverte : 206-232.

Dobres, Marcia-Anne, 2000, Technology and Social Agency. Oxford \& Malden (Mass.), Blackwell Publishers.

Douglas, Mary \& Baron Isherwood, 1979, The World of Goods : Towards an Anthropology of Consumption. Londres, Allen Lane.

Fabian, Johannes, 2004, « On Recognizing Things : The "Ethnic Artefact" and the "Ethnographic Object", L'Homme $\mathrm{n}^{\circ} 170$ : 25-46.

Faure-Rouesnel, Laurence, 2001, « French Anthropology and Material Culture », Journal of Material Culture $6(2): 237-47$. 
Forge, Anthony, 1962, « La Peinture, substance magique », Palette 9: 9-16.

Foucault, Michel, 1989, Résume des cours 1970-1982. Paris, Gallimard.

Gell, Alfred, 1988, « Technology and Magic », Anthropology Today 4, 2: 6-9.

Gell, Alfred, 1992, "The Technology of Enchantment and the Enchantment of Technology », in Jeremy Coote \& Anthony Shelton eds., Anthropology Art and Aesthetics. Oxford, Clarendon Press : 40-63.

Gell, Alfred, 2009 [1998], L’Art et ses agents. Dijon, Les Éditions du Réel.

Geslin, Philippe, 2002, «Les Formes sociales d'appropriations des objets techniques ou le paradigme anthropotechnologique », Ethnographiques.org n 1 , avril 2002 [en ligne]. (http ://www. ethnographiques.org/2002/ Geslin - consulté le 7.05.2010).

Glock, Hans-Johann, 2003 [1996], Dictionnaire wittgensteinien. Paris, Gallimard.

Godelier, Maurice, 1969, « La "Monnaie de sel" chez les Baruya de Nouvell Guinée », L’Homme 9 (2) : 5-37.

Godelier, Maurice \& Garanger, José, 1973, « Outils de pierre, outils d'acier chez les Baruya de NouvelleGuinée », L'Homme n 13 (3) : 187-220.

Gosden, Chris, 1999, Anthropology and Archaeology : a Changing Relationship. Londres \& New York, Routledge.

Gregory, Chris A., 1980, « Gifts to Men and Gifts to God : Gift Exchange and Capital Accumulation in Contemporary Papua », Man 15 (4) : 626-52

Gregory, Chris A., 1982, Gifts and Commodity. Londres, Academic Press.

Haudricourt, André-George, 1968, « La Technologie Culturelle : Essai de Méthodologie », in Poirier, Jean ed., Ethnologie Générale. Paris, Gallimard, Encyclopédie de la Pléiade : 731-880.

Haudricourt, André-George, 1987, La Technologie, science humaine: Recherche d'histoire et d'ethnologie des techniques. Paris, Éditions de la Maison des sciences de l'homme.

Hirsch, Eric, 1995, « The Coercive Strategies of Aesthetics : Reflections on Wealth, Ritual and Landscape in Melanesia », in J. F. Weiner ed., Too Many Meanings : A Critique of the Anthropology of Aesthetics. Social Analysis, $\mathrm{n}^{\circ}$ 38. Adelaide, University of Adelaide, Department of Anthropology : 61-71.

Hughes, Thomas P, 1986, «The Seamless Web : Technology, Science, Etcetera, Etcetera », Social Studies of Science $16: 281-92$.

Inglod, Tim, 2000 [1989], « Tools, Minds and Machines : an Excursion in the Philosophy of Technology » in Tim Ingold ed., The Perception of the Environment : Essays on Livelihood, Dwelling and Skill. Londres \& New York, Routledge : 294-311. (paru pour la première fois dans Techniques \& culture nº 12 : 151-176).

Ingold, Tim, 2007, « Materials Against Materiality », Archaeological Dialogues 14 (1) : 1-16.

Jackson, Michael, 1996, "Introduction : Phenomelogy, Radical Empiricism and Anthropological Critique », in Michael Jackson ed., Things as They Are: New Directions in Phenomenological Anthropology. Bloomington \& Indianapolis, Indiana University Press : 1-50.

Joulian, Frédéric, 1994, « Peut-on parler d'un système technique chimpanzé. Primatologie et archéologie comparées », De la Préhistoire aux missiles balistiques. L’intelligence sociale des techniques, Bruno Latour \& Pierre Lemonnier eds. Paris, La Découverte : 45-64.

Joulian, Frédéric \& Suzanne de Cheveigné eds., 2008, Les Natures de l'homme, Techniques \& culture n 50. Paris, Les Éditions de la Maison des sciences de l'homme.

Julien, Marie-Pierre \& Jean-Pierre Warnier, 1999, Approches de la culture matérielle. Corps-à-corps avec l'objet. Paris, L'Harmattan.

Julien, Marie-Pierre \& Rosselin, Céline, 2005, La Culture matérielle. Paris, La Découverte.

Julien, Marie-Pierre \& Rosselin, Céline eds., 2009, Le Sujet contre les objets... tout contre : Ethnographies de cultures matérielles. Paris, CTHS.

Julien, Marie-Pierre \& al., 2003, "Chantier ouvert au public », Techniques \& culture n 40, Efficacité technique, efficacité sociale (mis en ligne le 7 juin 2006. <URL : http ://tc.revues.org/document1559. html. consulté le 29 septembre 2008>).

Keane, Webb, 2005, « Signs Are Not the Garb of Meaning: On the Social Analysis of Material Things », in Daniel Miller ed., Materiality. Durham \& Londres, Duke University Press : 182-205.

Kirshenblatt-Gimblet, Barbara, 1998, Destination culture: Tourism, Museums and Heritage. Berkeley, Los Angeles, University of California Press. 
Kopytoff, Igor, 1986, "The Cultural Biography of Things: Commoditization as Process», in Arjun Appadurai ed., The Social Life of Things : Commodities in Cultural Perspective. Cambridge, Cambridge University Press : 65-91.

Kramer, Carol ed., 1979, Ethnoarchaeology: Implications of Ethnography for Archaeology. New York, Columbia University Press : 72-101.

Latour, Bruno, 1990, "Drawing things together », in Lynch, M. \& Woolgar, S. eds., Representation in Scientific Practice. Cambridge, MA,The MIT Press : 19-68

Latour, Burno, 1992, Aramis ou l'amour des techniques. Paris, La Découverte.

Latour, Bruno, 1996, «Lettre à mon ami Pierre sur l'anthropologie symétrique », Ethnologie Française n 26 (1) : 32-36.

Latour, Bruno \& Pierre Lemonnier eds., 1994, De la Préhistoire aux missiles balistiques. L'intelligence sociale des techniques. Paris, La Découverte.

Latour, Bruno \& Steve Woolgar, 1979, Laboratory Life : the Social Construction of Scientific Facts. Los Angeles $\&$ Londres, Sage.

Law, John, 1992, " Notes on the Theory of the Actor-network : Ordering, Strategy, and Heterogeneity ", Systems Practice 5 (4) : 379-93.

Leach, James, 2002, «Drum and Voice. Aesthetics, Technology, and Political Relations in a Rai Coast (Papua New Guinea) Society », Journal of the Royal Anthropologic Institute 8 (4) : 713-734.

Lechtman, Heather \& Robert Merrill eds., 1977, Material Culture: Styles, Organization and Dynamics of Technology. St Paul, Xest.

Lechtman, Heather, 1977, « Style in Technology - Some Early Thoughts », in Heather Lechtman \& Robert Merrill eds., Material Culture : Styles, Organization and Dynamics of Technology. St Paul, Xest : 3-20.

Lemonnier, Pierre, 1986, « The Study of Material Culture Today : toward an Anthropology of Technical Systems », Journal of Anthropological Archaeology 5 (2) : 147-86.

Lemonnier, Pierre, 1992, Elements for an Anthropology of Technology. Ann Arbor, University of Michigan Press.

Lemonnier, Pierre, 1993, Technological Choices. Transformation in Material Cultures Since the Neolithic. Londres, Routledge.

Lemonnier, Pierre, 1996, "Et pourtant ça vole : L'Ethnologie des techniques et les objets industriels ", Ethnologie Française n 26 (1) : 17-31.

Leroi-Gourhan, André, 1964, Le Geste et la Parole. Paris, Albin Michel.

Leroi-Gourhan, André, 1967, Treasures of Prehistoric Art. New York, Abrams.

Mackenzie, Maureen. A., 1991, Androgynous Objects : String Bags and Gender in Central New Guinea. Chur, Switzerland \& Reading, Harwood Academic.

Mattelart, Armand \& Érik Neveu, 1996, «Cultural studies' stories. La modernisation d'une pensée sauvage? », Réseaux n 80 : 11-58.

Mauss, Marcel. 1950, [1923-1924], «L'Essai sur le don : Forme et raison de l'échange dans les sociétés archaiques », in Marcel Mauss, Sociologie et anthropologie. Paris, PUF : 145-279.

Mauss, Marcel, 1968 [1909], Guvres. Tome I : Les Fonctions sociales du sacré. Paris, Éditions de Minuit : 357-477.

Miller, Daniel, 1987, Material Culture and Mass-Consumption. Oxford, Blackwell.

Miller, Daniel, 1995, « Consumption and Commodity » Annual Review of Anthropology 24 : 141-161.

Miller, Daniel ed., 1998, Material Cultures: Why some Things Matter. Chicago, The University of Chicago Press.

Miller, Daniel ed., 2005, Materiality. Durham \& Londres, Duke University Press.

Miller, Daniel, 2008, The Comfort of Things. Cambridge, Polity Press.

Mitcham, Carl \& Robert Mackey eds., 1972, Philosophy and Technology: Readings in the Philosophical Problems of technology. New York, Free Press.

Mumford, Lewis, 1950, Technique et civilisation. Paris, Seuil.

Munn, Nancy D., 1977, « The Spatiotemporal Transformations of Gawa Canoes », Journal de la Société des Océanistes $33: 39-52$

Naji, Myriem \& Laurence Douny, 2009, «Editorial », Journal of Material Culture 14 (4) : 411-432.

Parlebas, Pierre, 1999, Le Corps et le langage : parcours accidentés. Paris, L'Harmattan. 
Pfaffenberger, Bryan, 1988, «Fetishized Objets and Humanized Nature : Towards an Anthropology of Technology », Man 23 : 236-52.

Pfaffenberger, Bryan, 1990, "The Hindu Temple as a Machine, or the Western Machine as a Temple », Techniques E culture $n^{\circ} 16: 183-202$.

Pfaffenberger, Bryan, 1992, «Social Anthropology of Technology », Annual Review of Anthropology n 21 : 491-516.

Roscoe, Paul, 1995, « Of Power and Menace : Sepik Art as an Affecting Presence », The Journal of the Royal Anthropological Institute 1 (1) : 1-22.

Rowlands, Michael \& Jean-Pierre Warnier, 1995, «The Magical Production of Iron in the Cameroon Grassfield », in Thrustan Shaw E al., The Archaeology of Africa. Food, Metals and Towns. Londres, Routledge ; One World Archaeology 20 : 512-50.

Sassatelli, Roberta, 2007, Consumer culture: History, Theory and Politics. Londres, Sage.

Schiffer, Michael, 1992, Technological Perspective On Behavioral Change. Tucson, Arizona, The University of Arizona Press.

Schiffer, Michael ed., 2001, Anthropological Perspectives on Technology. Albuquerque, University of New Mexico Press.

Schlanger, Nathan \& Anthony Sincclair eds., 1990, Technology in the Humanities, Archaeological Review from Cambridge 9 (1).

Segalen, Martine, 2005, Vie d’un musée 1937-2005. Paris, Stock.

Sigaut, François, 1985, « More (and Enough) on Technology! », in History and Technology, vol.2 : 115-32.

Sigaut, François, 2002 [1994], « Technology», in Tim Ingold ed., Companion Encyclopedia of Anthropology. Londres, Routledge : 420-59.

Sigaut, François, 2002, «La Formule de Mauss », Techniques E culture n 40 : 153-165.

Sillar, Bill \& Michael S. Tite, 2000, «The Challenge of "Technological Choice" For Materials Science Approaches in Archaeology », Archaeometry 42 (1) : 2-20.

Sillitoe, Paul, 1988, Made in Niugini : Technology in the Highlands of Papua New Guinea. Londres, (Published for the Trustees of the British Museum by British Museum Publications in association with the University of Durham Publications Board).

Slater, Don, 1997, Consumer culture and modernity. Cambridge, Polity Press.

Staudenmaier, John M., 1990, « Recent Trends in the History of Technology », American Historical Review $95: 715-25$.

Steiner Christopher \& Philipps Ruth eds., 1999, Unpacking Culture : Art and Commodity in Colonial and Postcolonial Worlds. Berkeley, University of California Press.

Stocking, Georg W., Jr. ed., 1985, «Objects and Others : Essays on Museums and Material Culture », History of Anthropology vol. 3. Madison, The University of Wisconsin Press.

Strathern, Marilyn, 1991, «Parts and Whole: Refiguring Relationships in a Post-plural World », in A. Kuper ed., Conceptualizing Society. New York \& Londres, Routledge : 75-104.

Strum, Shirley, 1994, «Une Société complexe sans culture matérielle. Le cas des babouins », De la Préhistoire aux missiles balistiques. L'intelligence sociale des techniques, Bruno Latour \& Pierre Lemonnier eds. Paris, La découverte : 27-44.

Sturtevant, William C., 1969, « Does Anthropology need Museums? », Proceedings of the Biological Society of Washington 82 : 619-50.

Thomas, Nicholas, 1991, Entangled Objects : Exchange, Material Culture, and Colonialism in the Pacific. Cambridge, Mass \& Londres, Harvard University Press.

Tilley, Christopher, 1994, A Phenomenology of Landscape : Places, Paths, and Monuments. Oxford, Berg.

Tilley, Christopher, 2004. The Materiality of Stone: Explorations in Landscape Phenomenology. Oxford, Berg.

Ucko, Peter, 1969, « Penis Sheaths : A Comparative Study », The Curl Lecture 1969. Proceedings of the Royal Anthropological Institute of Great Britain and Ireland : 24-67.

Van der Leeuw, Sander E., 1976, Studies in the Technology of Ancient Pottery. Amsterdam, Université d'Amsterdam (thèse de doctorat). 
Van der Leeuw, Sander E, 1991, "Variation, Variability and Explanation in Pottery Studies », in W. A Longacre ed., Ceramic Ethnoarchaeology. Tucson, University of Arizona Press : 11-39.

Van der Leeuw, Sander E., Dick A. Papousek \& Anick Coudart, 1992, « Technical Traditions and Unquestioned Assumptions : the Case of Pottery in Michoacan $»$, Techniques \& culture n 17-18 : 145-173.

Warnier, Jean-Pierre,1999, Construire la culture matérielle : L'Homme qui pensait avec ses doigts. Paris, P.U.F.

Warnier, Jean-Pierre, 2009, "Technology as Efficacious Action on Objects... and Subjects », Journal of Material Culture 14 (4) : 459-470.

Weiner, James F., 1995, « Technology and Techne in Trobriand and Yolngu Art », in James Weiner ed., 1995, Too Many Meanings : A Critique of the Anthropology of Aesthetics. Social Analysis n 38. Adelaide, University of Adelaide, Department of Anthropology : 32-46.

White, Leslie. A, 1959, The Evolution of Culture: The Development of Civilization to the Fall of Rome. New York, McGraw-Hill.

Whitehead, Alfred North, 1997 [1925], Science and the Modern World. Londres, Free Press (Simon \& Schuster).

Wittgenstein, Ludwig, 1993 [1922], Tractatus Logico-Philosophicus. Paris, Gallimard.

Yellen, John E., 1977, Archaeological approaches to the present. Models for reconstructing the past, Londres \& New-York, Academic Press.

\section{RÉSUMÉ}

Dans la trajectoire des choses. Comparaison des approches francophones et anglophones contemporaines en anthropologie des techniques. Dans cette introduction, les auteurs exposent les approches francophones et anglophones de l'étude des techniques et suggèrent que ces deux traditions ont traité d'enjeux comparables. Ils les resituent dans l'histoire des Sciences humaines et analysent leur place dans le champ anthropologique. Ils retracent les débats et les échanges qui les ont enrichies, particulièrement dans leur dialogue avec d'autres disciplines connexes comme l'archéologie, la sociologie, l'Histoire de l'Art et la muséologie. En conclusion, les auteurs suggèrent que l'un des éléments qui différencie ces traditions réside dans la manière dont est pensée et traitée la question du déterminisme.

\section{ABSTRACT}

Within the Trajectory of Things. Perspectives on anglophones and francophones anthropological approaches of techniques and technology. In this introduction, the authors present francophones and anglophones approaches of the study of techniques and suggest that both traditions have dealt with comparable questions. They replace these approaches in the history of social sciences, and analyse their position in the field of anthropology. They summarise some of the debates and > exchanges that have enrich them, in particular during the dialogues with disciplines such as archaeology, sociology, art history and museology. As a conclusion, the authors suggest that one of the elements that help distinguishing these traditions can be found in the way in which they have tackled the question of determinism.

\section{MOTS CLÉS}

Anthropologie francophone, anthropologie anglophone, Material Culture Studies, culture matérielle, technologie culturelle.

\section{KEYWORDS}

Francophone Anthropology, Anglophone Anthropology, Material Culture Studies, Culture Matérielle, Technologie Culturelle. 